OPEN ACCESS

Edited by:

Katrin Kierdorf,

University of Freiburg, Germany

Reviewed by:

Angela Giangrande,

Conseil National Pour La Recherche

Scientifique, France

Jonathon Coates,

Queen Mary University of London, United Kingdom

*Correspondence: Katja Brückner

katja.brueckner@ucsf.edu

${ }^{\dagger}$ These authors have contributed equally to this work

Specialty section:

This article was submitted to Cell Death and Survival,

a section of the journal

Frontiers in Cell and Developmental

Biology

Received: 17 November 2020 Accepted: 25 January 2021

Published: 11 March 2021

Citation:

Mase A, Augsburger $J$ and Brückner K (2021) Macrophages and Their Organ Locations Shape

Each Other in Development and Homeostasis - A Drosophila

Perspective.

Front. Cell Dev. Biol. 9:630272. doi: 10.3389/fcell.2021.630272

\section{Macrophages and Their Organ Locations Shape Each Other in Development and Homeostasis - A Drosophila Perspective}

\author{
Anjeli Mase ${ }^{1 \dagger}$, Jordan Augsburger ${ }^{1+}$ and Katja Brückner ${ }^{1,2,3 *}$ \\ ${ }^{1}$ Department of Cell and Tissue Biology, University of California, San Francisco, San Francisco, CA, United States, ${ }^{2}$ Eli \\ and Edythe Broad Center of Regeneration Medicine and Stem Cell Research, University of California, San Francisco, \\ San Francisco, CA, United States, ${ }^{3}$ Cardiovascular Research Institute, University of California, San Francisco, \\ San Francisco, CA, United States
}

Across the animal kingdom, macrophages are known for their functions in innate immunity, but they also play key roles in development and homeostasis. Recent insights from single cell profiling and other approaches in the invertebrate model organism Drosophila melanogaster reveal substantial diversity among Drosophila macrophages (plasmatocytes). Together with vertebrate studies that show genuine expression signatures of macrophages based on their organ microenvironments, it is expected that Drosophila macrophage functional diversity is shaped by their anatomical locations and systemic conditions. In vivo evidence for diverse macrophage functions has already been well established by Drosophila genetics: Drosophila macrophages play key roles in various aspects of development and organogenesis, including embryogenesis and development of the nervous, digestive, and reproductive systems. Macrophages further maintain homeostasis in various organ systems and promote regeneration following organ damage and injury. The interdependence and interplay of tissues and their local macrophage populations in Drosophila have implications for understanding principles of organ development and homeostasis in a wide range of species.

\footnotetext{
Keywords: Drosophila melanogaster, macrophage, plasmatocyte, hemocyte, organ microenvironment, regeneration, development, homeostasis
}

\section{INTRODUCTION}

Macrophages have a wide range of functions across species. While best known for their roles in innate immunity, macrophages also perform vital tissue-specific roles in development and homeostasis (Gold and Brückner, 2015; Okabe and Medzhitov, 2016). At the same time, macrophages are defined by their local microenvironments (Lavin et al., 2015). In this review, we discuss these underappreciated dual ways that macrophages and their microenvironment shape one another, focusing on insights from the invertebrate model organism Drosophila melanogaster.

The Drosophila blood cell system closely parallels the hematopoietic system of vertebrates both developmentally and functionally, making it an especially apt model for studying macrophage development, heterogeneity, and function (Hartenstein, 2006; Gold and Brückner, 2014, 2015; Banerjee et al., 2019). Since the 1970s, the concept of the mononuclear macrophage system 
dominated the vertebrate field, proposing that hematopoietic progenitors of the bone marrow give rise to monocytes, which are the source of all macrophages as they enter the tissues (van Furth et al., 1972; Dzierzak and Speck, 2008; Morrison and Scadden, 2014). However, over the last decade or more, this view has been dismissed in favor of a new model of two independent lineages of macrophages (Frame et al., 2013; Lavin et al., 2015; Ginhoux et al., 2016; Perdiguero and Geissmann, 2016). Based on modern genetic lineage tracing, an independent lineage of blood cells gives rise to the majority of tissueresident macrophages in vertebrates. This independent lineage derives from erythro-myeloid progenitors that originate in the embryonic yolk sac and mature in the fetal liver, and subsequently colonize organs throughout the body, giving rise to local macrophage populations such as the microglia of the brain, Langerhans cells of the skin, Kupffer cells of the liver, and resident macrophages of the lung (Herbomel et al., 2001; Merad et al., 2002; Ajami et al., 2007; Geissmann et al., 2010; Hoeffel et al., 2012; Schulz et al., 2012; Davies et al., 2013; Hashimoto et al., 2013; Sieweke and Allen, 2013; Gomez Perdiguero et al., 2015). In some, but not all, organs this independent lineage of tissue macrophages is complemented by macrophages of the monocyte lineage (Davies et al., 2013; Frame et al., 2013; Sieweke and Allen, 2013; Lavin et al., 2015; Ginhoux et al., 2016; Perdiguero and Geissmann, 2016).

Interestingly, much like vertebrates, Drosophila also has two independent lineages of blood cells, or hemocytes:

(1) The embryonic/resident lineage, which parallels the vertebrate erythro-myeloid progenitor lineage of tissue macrophages, is based on self-renewing differentiated macrophages (Makhijani et al., 2011; Davies et al., 2013; Gold and Brückner, 2014, 2015; Ratheesh et al., 2015; Banerjee et al., 2019). Hemocytes of this lineage arise in the embryonic head mesoderm, quickly differentiate into macrophage-like plasmatocytes, migrate throughout the embryo in stereotyped routes (Tepass et al., 1994; Siekhaus et al., 2010), and then colonize organ and tissue microenvironments in the larva where they proliferate over time (Gold and Brückner, 2014, 2015). Examples include the prominent tissue-resident clusters of hemocytes in segmentally repeated epidermal-muscular pockets (hematopoietic pockets), and resident hemocytes at the proventriculus of the gastrointestinal system (Zaidman-Rémy et al., 2012). Homing and adhesion of hemocytes to these sites depends on active sensory neurons of the hematopoietic pockets and their expression of the Transforming Growth Factor- $\beta$ (TGF$\beta$ ) family ligand Activin- $\beta$ (Act $\beta$ ) and other predicted factors (Makhijani et al., 2011, 2017). Neuron signals may also play a role in the localization of hemocytes at the proventriculus (Cognigni et al., 2011). In hemocytes, actin cytoskeleton regulators such as Rhol and Rac appear to be required for their tissue localization and adhesion (Williams, 2006; Makhijani et al., 2011). Likewise, Nimrod family transmembrane receptors such as Nimrod C1 (NimC1) and Eater, expressed on plasmatocytes, play roles in adhesion (Bretscher et al., 2015; Melcarne et al., 2019), the latter through interaction with the collagen XV/XVIII ortholog
Multiplexin in the basement membrane of tissues (Csordás et al., 2020). Hemocyte adhesion is negatively regulated by factors from other tissues such as NimB5, secreted from the fat body upon nutrient starvation, driving hemocyte release into circulation (Ramond et al., 2020b). Resident hemocytes also lose adhesion and enter circulation upon various immune challenges, or changes in cell signaling (Williams, 2006; Stofanko et al., 2008; Markus et al., 2009), while wounds induce local adhesion of circulating hemocytes (Babcock et al., 2008). However, under unchallenged conditions, in the first and second instar larva, the vast majority of hemocytes are resident (Makhijani et al., 2011; Petraki et al., 2015). Starting in the late second to early third instar, an increasing number of hemocytes enter circulation (Markus et al., 2009; Makhijani et al., 2011; Petraki et al., 2015), establishing a steady state exchange with various resident locations (Welman et al., 2010; Makhijani et al., 2011; Makhijani and Brückner, 2012).

(2) The lymph gland lineage, which is based on progenitors, parallels the vertebrate lineage of hematopoietic stem and progenitor cells (Jung, 2005; Krzemien et al., 2010a,b; Gold and Brückner, 2014; Banerjee et al., 2019). Developmentally, the lymph gland originates from the cardiogenic mesoderm of the embryo, echoing the emergence of hematopoietic stem cells from the endothelium of the aorta in vertebrates (Hartenstein, 2006; Gold and Brückner, 2014, 2015; Banerjee et al., 2019). Blood progenitors of the lymph gland proliferate in the embryo and the larval stages, and only start in the mid-second instar to differentiate into plasmatocytes and other immune cell types (Jung, 2005; Krzemien et al., 2010a; Gold and Brückner, 2015; Banerjee et al., 2019). In addition, differentiated plasmatocytes proliferate to a certain extent, in particular in third instar larvae (Jung, 2005; Banerjee et al., 2019). Immune assaults and environmental challenges accelerate the differentiation of lymph gland progenitors and the release of differentiated plasmatocytes and other immune cells into circulation (Sorrentino et al., 2002; Crozatier et al., 2004; Márkus et al., 2005; Owusu-Ansah and Banerjee, 2009; Shim et al., 2013; Letourneau et al., 2016; Banerjee et al., 2019). Likewise, dysregulation of various major signaling pathways that usually tightly control normal lymph gland development can result in premature, or precocious, differentiation, including signaling by Notch $(\mathrm{N})$, Hedgehog (Hh), Wingless (Wg), the Bone Morphogenetic Protein (BMP) Decapentaplegic (Dpp), receptor tyrosine kinases such as the PDGFR/VEGFR-related Receptor (PVR) and Fibroblast Growth Factor Receptor (FGFR), Hippo, JAK/STAT, NFкB- related Toll signaling and transcriptional regulators such as the zinc finger transcription factor Zfrp8 and the GATA factor Pannier (Qiu et al., 1998; Myrick and Dearolf, 2000; Lebestky et al., 2003; Crozatier et al., 2004; Mandal et al., 2007; Minakhina et al., 2007, 2011; Sinenko et al., 2009; Pennetier et al., 2012; DragojlovicMunther and Martinez-Agosto, 2013; Ferguson and MartinezAgosto, 2014; Milton et al., 2014; Destalminil-Letourneau et al., 2021). In contrast, under unchallenged conditions, the lymph gland disintegrates and releases all of its hemocytes at the beginning of metamorphosis (Grigorian et al., 2011). 
The two hemocyte lineages persist into the adult animal, with the embryonic lineage contributing the major part of immune cells, at least under unchallenged conditions ( $\mathrm{Holz}$ et al., 2003; Sanchez Bosch et al., 2019). No significant new blood cell production has been detected in the adult, even under conditions of immune challenge (Sanchez Bosch et al., 2019), and a decline in both hemocyte number and phagocytic activity has been documented as adult flies age (Mackenzie et al., 2011; Horn et al., 2014). Both hemocyte lineages give rise to common cell types: plasmatocytes ( $>90 \%$ of immune cells at most developmental stages), which are analogous to vertebrate macrophages and function as the primary phagocytic cells in Drosophila; crystal cells ( $\sim 5 \%$ of immune cells), which function in clotting and wound healing through prophenoloxidase (PPO)mediated melanization; and lamellocytes, stress- or immune challenge-induced cells involved in encapsulation, analogous to granuloma formation in vertebrates (Gold and Brückner, 2014, 2015; Banerjee et al., 2019).

Across species, macrophages have many important functions during development and homeostasis (Figure 1). Macrophages play vital roles in phagocytosis of pathogens and apoptotic cells, through scavenger receptors such as Croqumort (Crq), and Nimrod-domain (NIM) containing receptors including Eater, Nimrod C1 (NimC1), Draper (Drpr), and Six-microns-under (Simu) (Franc, 1999; Manaka et al., 2004; Kocks et al., 2005; MacDonald et al., 2006; Kurucz et al., 2007; Kurant et al., 2008; Krzemien et al., 2010b; Melcarne et al., 2019; Roddie et al., 2019). Related to this, macrophages participate in wound healing (Stramer et al., 2005; Babcock et al., 2008; PastorPareja et al., 2008; Koh and DiPietro, 2011; Wang et al., 2014). They play a central role in innate immunity, producing antimicrobial and pro-inflammatory mediators (Lemaitre and Hoffmann, 2007; Lazzaro, 2008; Buchon et al., 2014). In addition, macrophages have homeostatic functions such as regulation of dietary stress (Woodcock et al., 2015) and detection and regulation of the metabolic state (Parupalli et al., 2020). Drosophila macrophages also produce and deposit extracellular matrix (ECM) components (Fessler and Fessler, 1989; Wood and Jacinto, 2007) such as Collagen IV, Laminin, Perlecan, and Peroxidasin, an ECM-associated peroxidase, as they migrate along surfaces and reside in specific anatomical locations (Nelson et al., 1994; Bunt et al., 2010; Martinek et al., 2011; Van De Bor et al., 2015; Matsubayashi et al., 2017; Sánchez-Sánchez et al., 2017). Moreover, Drosophila macrophages regulate stem cells and other tissue-specific cell populations, often through localized secretion of signals such as cytokines of the Unpaired (Upd) family, which signal through the receptor Domeless (Dome) and the JAK/STAT pathway (Hopscotch and Stat2E in Drosophila), promoting proliferation and differentiation of target tissues (Chakrabarti et al., 2016; Guillou et al., 2016). In Drosophila, at least some macrophage-like plasmatocytes have the plasticity to give rise to crystal cells (Bretscher et al., 2015; Leitão and Sucena, 2015; Corcoran et al., 2020) and, upon immune challenge, lamellocytes (Markus et al., 2009; Anderl et al., 2016).

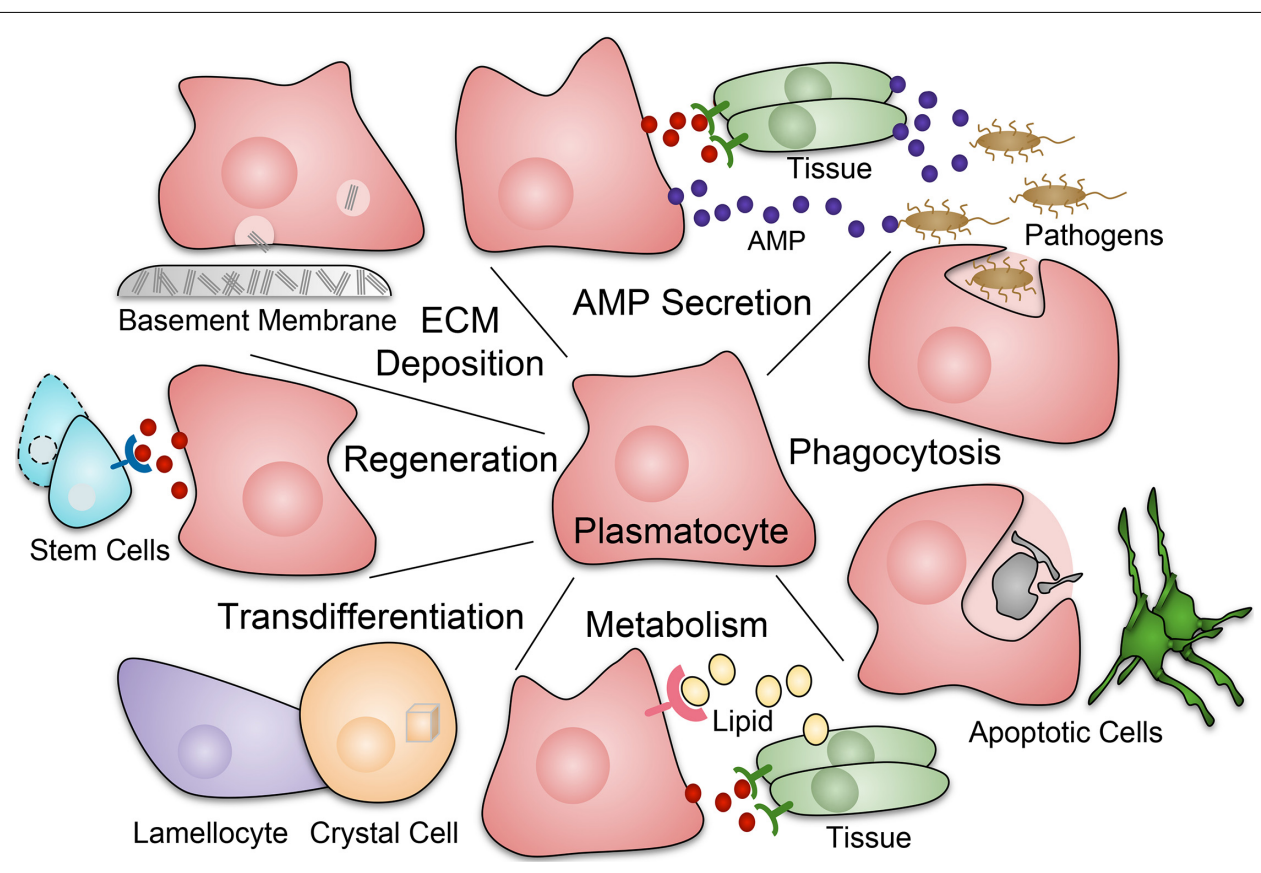

FIGURE 1 | Roles of macrophage-like plasmatocytes in Drosophila. Plasmatocytes (red) perform a diverse array of functions during development, homeostasis, injury, and infection. Responses include phagocytosis of pathogens and apoptotic cells; production of AMPs (antimicrobial peptides) and inflammatory mediators; production and deposition of ECM (extracellular matrix) components such as collagen that are often part of the basement membrane; tissue repair and regeneration, including stimulation of stem cell function; roles in metabolic homeostasis including uptake of lipids and secretion of metabolic mediators. In addition, at least some Drosophila plasmatocytes have plasticity to transdifferentiate into other hemocyte types, specifically crystal cells and, upon immune challenge, lamellocytes. 


\section{NEW INSIGHTS INTO MACROPHAGE DIVERSITY}

A recent body of research suggests that not all macrophages are equal, rather they can be categorized into phenotypically and functionally unique subpopulations. Single cell RNA sequencing and functional studies in Drosophila identify transcriptionally and functionally distinct clusters of plasmatocytes, which are modulated by developmental time, lineage, injury, and infection status (Cattenoz et al., 2020; Cho et al., 2020; Coates et al., 2020; Ramond et al., 2020a; Tattikota et al., 2020). Vertebrate single cell studies identify similar heterogeneity among macrophages, modulated by developmental stage and lineage (Gordon and Taylor, 2005; Martinez et al., 2006; Paul et al., 2015; Lin et al., 2019; Lantz et al., 2020). Under pathologic conditions, macrophages may take on a spectrum of activation states, mirrored by their transcriptional profiles, dependent on disease severity (Lin et al., 2019; Mould et al., 2019; Weinstock et al., 2019; Lantz et al., 2020). Additionally, through analyses of enhancer landscapes and tissue-specific single cell RNA sequencing, it has become clear that macrophage subpopulations of organs including the liver, spleen, lung, peritoneal cavity, colon, small intestine, brain, and kidney, are shaped by their tissue of residence in vertebrate models (Gosselin et al., 2014; Lavin et al., 2014; MacParland et al., 2018; Mould et al., 2019; Van Hove et al., 2019; Zimmerman et al., 2019). In Drosophila, it is expected that heterogeneity of macrophages stems from the complex interactions between these cells and their microenvironment. A recent sequencing study identified cross-species markers between Drosophila and vertebrate macrophages, although their functional significance remains to be determined (Fu et al., 2020).

In addition to parallels in the local regulation of macrophages, Drosophila and vertebrates rely on conserved systemic signaling that regulates macrophages. Vertebrate macrophages express colony stimulating factor 1 receptor (CSF-1R), a receptor tyrosine kinase (RTK) of the family of Platelet-Derived Growth Factor Receptors and Vascular Endothelial Growth Factor Receptors (PDGFRs and VEGFRs) (Lemmon and Schlessinger, 2010). Vertebrate CSF-1R is activated by colony-stimulating factor-1 (CSF-1) and interleukin-34 (IL-34), promoting proliferation, differentiation, survival, chemotactic migration and differentiation of macrophages during development, homeostasis, and innate immunity (Stanley and Chitu, 2014). Similarly in Drosophila, the molecularly conserved ortholog PDGFR/VEGFR-related Receptor (PVR) is expressed in hemocytes. PVR recognizes PDGF/VEGF related factors Pvf1, Pvf2, and Pvf3, and is essential for trophic survival, proliferation, plasmatocyte activation, and some aspects of chemotactic migration (Munier et al., 2002; Brückner et al., 2004; Wood et al., 2006; Wood and Jacinto, 2007; Kelsey et al., 2012; Parsons and Foley, 2013; Sopko et al., 2015).

Despite the apparent necessity of macrophages in development and homeostasis, ablation studies suggest that hemocytes are not essential for survival in Drosophila (Braun et al., 1998; Charroux and Royet, 2009; Defaye et al., 2009; Arefin et al., 2015). However, plasmatocytes and PVR expression are fundamental to embryonic development, as they promote the essential process of central nervous system (CNS) condensation (Zhou et al., 1995; Sears, 2003; Olofsson and Page, 2005; Defaye et al., 2009; Evans et al., 2010). Lack of macrophages is seemingly compatible with larval and pupal development, although it causes a shift in immune effector pathways - specifically, induction of the Toll pathway and repression of the Imd pathway - which leads to a proinflammatory state and aberrant leg development, in turn resulting in reduced likelihood of eclosion (Arefin et al., 2015). In adult Drosophila, lack of macrophages increases susceptibility to bacterial infection (Braun et al., 1998; Charroux and Royet, 2009; Defaye et al., 2009; Arefin et al., 2015), demonstrating their immune functions and role as sentinels of infection that induce antimicrobial peptide (AMP) gene expression in other tissues (Sanchez Bosch et al., 2019).

It is clear that plasmatocytes are a diverse population of cells that modulate a wide variety of processes during development. Genetic studies in Drosophila have provided broad evidence of tissue-specific macrophage function. How do macrophages and their microenvironment shape one another in different organ systems? We address this question in the following paragraphs and Figure 2.

\section{NERVOUS SYSTEM}

The Drosophila central nervous system consists of the brain and ventral nerve cord, and the peripheral nervous system includes sensory and motor neurons (Landgraf and Thor, 2006; SánchezSoriano et al., 2007; Hartenstein et al., 2008; Singhania and Grueber, 2014; Schirmeier et al., 2016; Doe, 2017; Li et al., 2018; Sugie et al., 2018; Akin and Zipursky, 2020). Major roles of macrophages in the nervous system, together with glia, are the phagocytic removal of apoptotic cells and the production of ECM (Zheng et al., 2017; Bittern et al., 2020; Hilu-Dadia and Kurant, 2020). Hemocytes invade the posterior end of the embryo during the germband extended stage and subsequently disperse throughout the embryo by migration, also entering the ventral nerve cord (VNC) (Tepass et al., 1994; Brückner et al., 2004). Some aspects of this migration, in particular invasion of the posterior end and migration along the VNC are mediated by PVR (Brückner et al., 2004; Wood et al., 2006), although PVR is primarily required for anti-apoptotic survival of hemocytes (Brückner et al., 2004). In the VNC, a significant amount of programmed cell death takes place in various cell types from the early stages of CNS formation to the end of embryogenesis (Abrams et al., 1993; White et al., 1994; Sonnenfeld and Jacobs, 1995; Zhou et al., 1995; Hidalgo et al., 2001; Peterson et al., 2002; Lundell, 2003; Miguel-Aliaga, 2004; Karcavich and Doe, 2005; Rogulja-Ortmann et al., 2007). Hemocytes phagocytose apoptotic bodies, opening up spaces and allowing for condensation of the nervous system (Olofsson and Page, 2005; Evans et al., 2010). Inhibition of hemocyte development or function causes mispositioning of glia, which, in turn, results in CNS axon scaffold and patterning defects (Sears, 2003); this phenotype is also observed when either PVR or Crq are RNAi silenced in hemocytes (Sears, 2003). CNS axon scaffold malformation forms a physical barrier to hemocyte migration along the VNC 


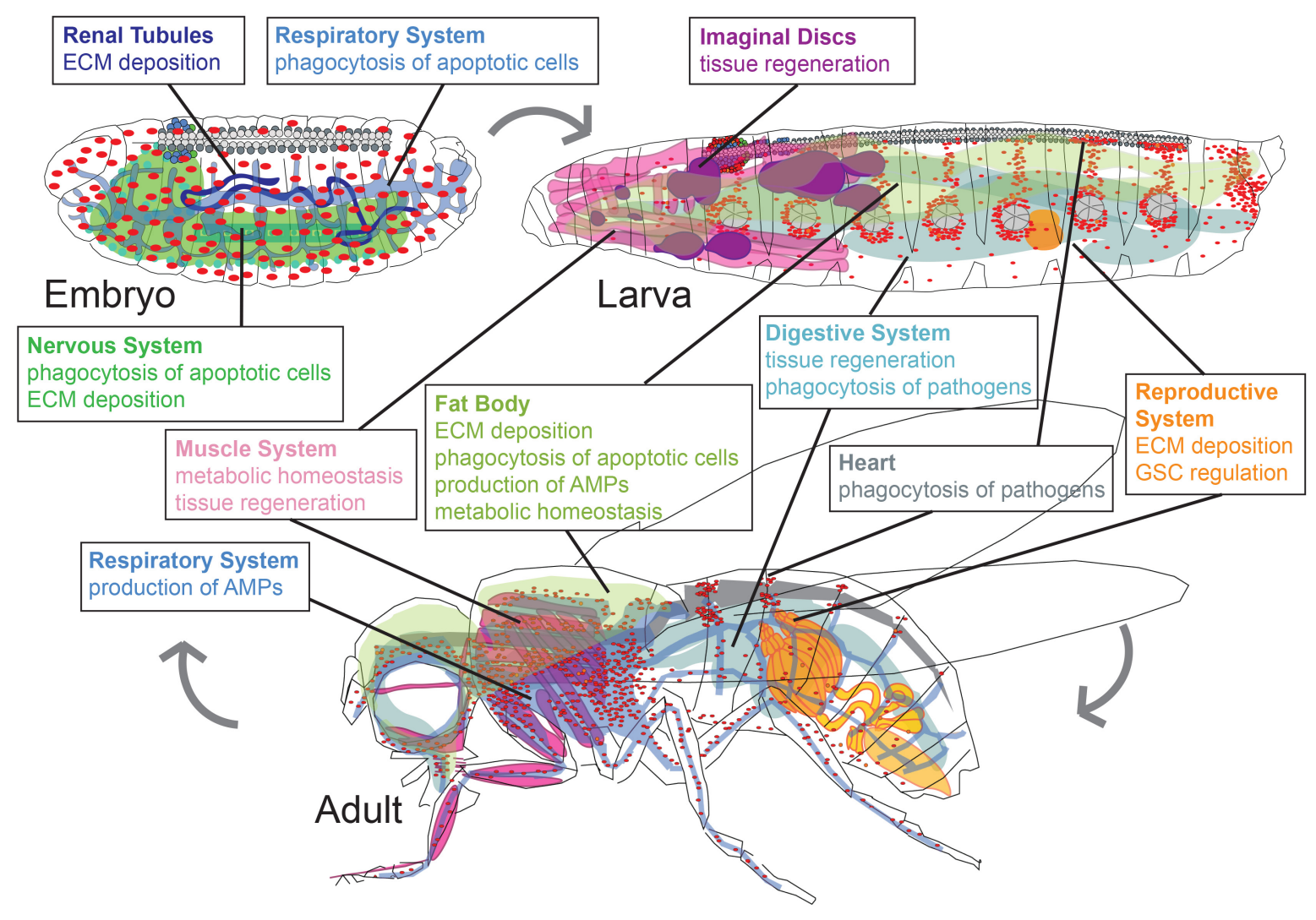

FIGURE 2 | Drosophila macrophages play life stage and tissue-specific roles in development, homeostasis, and infection. Major roles of plasmatocytes (macrophages, red) during developmental stages of embryo, larva, and adult (pupal stage is omitted). Organ systems regulated by macrophages are renal tubules (dark blue), respiratory system (light blue), nervous system (green), fat body (olive green), muscle system (pink), imaginal discs (purple), digestive system (teal), reproductive system (orange), heart (gray). Organ shapes adapted from Hartenstein (1995).

(Evans et al., 2010). When hemocytes cannot migrate, VNC condensation was proposed to also be disrupted due to a lack of ECM deposition by the migrating hemocytes (Olofsson and Page, 2005; Evans et al., 2010). Consistent with this, hemocytes deficient in laminin B1 (LanB1) exhibit slower migration along the ventral nerve cord (VNC) and defects in VNC condensation (Sánchez-Sánchez et al., 2017).

As development proceeds, in the larva, and especially during metamorphosis and in the adult, functions of hemocytes are more predominantly adopted by glia. In particular, glia mediate phagocytosis of dead cells and neuron fragments during axonal and dendrite pruning, and following injury (Sonnenfeld and Jacobs, 1995; Watts et al., 2004; Kurant, 2011; Bittern et al., 2020; Furusawa and Emoto, 2020; Hilu-Dadia and Kurant, 2020). Hemocytes and glia show molecular parallels regarding their phagocytic receptors such as Simu and Drpr (MacDonald et al., 2006; Kurant et al., 2008; Shklyar et al., 2014; Evans et al., 2015; Weavers et al., 2016; Shlyakhover et al., 2018; Davidson and Wood, 2020), and their mutual dependence on the transcription factors glial cells missing $(\mathrm{gcm})$ and glial cells missing $2(\mathrm{gcm} 2)$, during embryonic development (Bernardoni et al., 1997; Alfonso and Jones, 2002; Trébuchet et al., 2019).
Plasmatocytes also play roles in the development and homeostasis of the peripheral nervous system (PNS). During larval development, macrophages were proposed to function in neuronal pruning by severing destabilized dendritic branches and engulfing neuronal debris (Williams, 2005). More recently, however, it has been shown that non-traditional phagocytes, including glia and epidermal cells, play more central roles in neuronal pruning during development (Han et al., 2014). Macrophages may also have other roles in PNS development: a study suggested that hemocytes may promote aspects of glial cell biology necessary for peripheral nerve elongation (Pandey et al., 2011).

Conversely, the peripheral nervous system (PNS) can shape its resident macrophages and other hemocytes. Hemocytes associate with sensory neurons of the PNS in segmentally repeated hematopoietic pockets of the larval body wall (Makhijani et al., 2011; Makhijani and Brückner, 2012). These sensory neurons detect a variety of environmental and internal cues such as mechanical inputs, chemical stimuli, temperature, and light (Tracey et al., 2003; Hughes and Thomas, 2007; Song et al., 2007; Xiang et al., 2010; Han et al., 2014) and serve as a microenvironment for macrophages and other hemocytes (Makhijani et al., 2011, 2017; Makhijani and Brückner, 2012; 
Corcoran et al., 2020). Within the microenvironments, neurons promote macrophage survival (Makhijani et al., 2011) through Dscam1 expression (Ouyang et al., 2020), and proliferation and localization by the expression of Act $\beta$ (Makhijani et al., 2017). Moreover, a specific set of caudal sensory neurons promotes transdifferentiation of plasmatocytes into crystal cells in the presence of oxygen, providing evidence that environmental inputs to the sensory nervous system can impact hematopoietic processes (Corcoran et al., 2020).

\section{DIGESTIVE SYSTEM}

The digestive system of Drosophila is maintained throughout all developmental stages based on intestinal stem cell (ISC) proliferation and differentiation (Murakami et al., 1999; Micchelli and Perrimon, 2006; Ohlstein and Spradling, 2006; Lemaitre and Miguel-Aliaga, 2013). Macrophages and other hemocytes form aggregates in folds of the intestine: at all developmental stages, they are enriched at the proventriculus, a structure where the esophagus, crop, and midgut converge (Tepass et al., 1994; Lebestky et al., 2000; Brückner et al., 2004; Charroux and Royet, 2009; Zaidman-Rémy et al., 2012). Hemocytes at the proventriculus are regulated by phosphoinositide 3kinase (PI3K): PI3K signaling decreases hemocyte adhesion at the proventriculus, although it does not interfere with initial recruitment (Zaidman-Rémy et al., 2012). Hemocyte localization and responses may be further regulated by the innervation of the proventriculus (Cognigni et al., 2011), similar to hemocyte dependence on active sensory neurons in the hematopoietic pockets (Makhijani et al., 2011, 2017; Gold and Brückner, 2014, 2015). Macrophages are also enriched in clusters at the midgut, especially upon damage or infection (Ayyaz et al., 2015), and it has been debated whether some hemocytes are inserted in the midgut epithelium (Charroux and Royet, 2009; Zaidman-Rémy et al., 2012).

The macrophages of the intestine play important roles in innate immunity, maintaining homeostasis of gut microbiota both under basal conditions and after pathogen ingestion via the secretion of AMPs and phagocytosis (Nehme et al., 2007; Charroux and Royet, 2009; Ayyaz et al., 2015; Bonfini et al., 2016; Guillou et al., 2016). In addition, under conditions of tissue damage, inflammation, and infection, local and systemic macrophages function to promote and control tissue regeneration of the intestine (Takeishi et al., 2013; Ayyaz et al., 2015; Chakrabarti et al., 2016). Septic injury triggers upregulation of Upd ligands in hemocytes (PastorPareja et al., 2008; Chakrabarti et al., 2016), inducing systemic changes including intestinal stem cell activation via JAK/STAT signaling (Chakrabarti et al., 2016; Guillou et al., 2016); this mechanism plays a role in many situations of gut regeneration and homeostasis (Jiang et al., 2009). Upon gut damage by oxidative stress or oral infection, local hemocytes produce the BMP Dpp, inducing proliferation of ISCs through activation of the signal transducer dSmad2, followed by signaling through the signal transducer Mothers against Dpp (Mad) that restores ISC quiescence (Ayyaz et al., 2015). This pathway also maintains normal gut homeostasis and limits ISC proliferation (Guo et al., 2013; Zhou et al., 2015). As the fly ages, repeated Dpp secretion by hemocytes can lead to dysregulated $\mathrm{dSmad} 2$ activity, resulting in dysplasia as ISCs over-proliferate, an intriguing model for colon cancer (Ayyaz et al., 2015). Similarly, in mouse models, macrophages in the colon directly promote the proliferation of epithelial progenitors as a wound response (Pull et al., 2005).

\section{REPRODUCTIVE SYSTEM}

The Drosophila reproductive organs, the female ovary and the male testis, carry germline stem cells and produce the gametes (Fuller and Spradling, 2007). In the Drosophila ovary, the basement membrane, a specialized ECM underlying the basal side of epithelial cells (LeBleu et al., 2007; Yurchenco, 2011), is important for the stability and function of the gonad and the developing egg chambers (follicles) (Denef et al., 2008; Van De Bor et al., 2015). While follicular epithelial cells contribute to the basement membrane in the adult ovary (Denef et al., 2008), a population of ovarian macrophages deposits collagen IV in the larval gonad, forming a stable basement membrane that persists from the larval to the adult stage (Van De Bor et al., 2015). This basement membrane regulates the stem cell niche of the gonad by limiting diffusion of the BMP Dpp, which prevents excessive Dpp in the ovaries from triggering over-proliferation of the germline stem cells (Van De Bor et al., 2015). The gradient of Dpp is also known to be limited by heparan sulfate proteoglycans (HSPGs) (Guo et al., 2013; Zhou et al., 2015). In the absence of hemocyte-produced collagen, larvae develop malformed basement membranes, which, in turn, lead to dysregulated stem cell proliferation, ultimately resulting in decreased reproductive fitness (Wang et al., 2008; Van De Bor et al., 2015). In the male testis, macrophages were suggested to be required for the regeneration of germline stem cells from dedifferentiating spermatogonial cells, a process that may depend on JAK/STAT signaling (Varga et al., 2020). In the mammalian ovary, macrophages play various roles, although mechanistic parallels with Drosophila remain to be determined (Wu et al., 2004). For example, macrophages are located along the basement membrane and support follicular development during the estrous cycle (Cohen et al., 1997). Their exact role in tissue remodeling during ovulation is unclear, although mice lacking ovarian macrophages have decreased reproductive success (Cohen et al., 1997).

\section{RESPIRATORY SYSTEM}

The Drosophila respiratory system consists of a tubular system of trachea that develop over the embryonic and larval stages; it is then remodeled during metamorphosis, forming the extensive air sacs of the head and thorax, as well as tubular tracheal structures in the abdomen of the adult animal (Whitten, 1957; Manning and Krasnow, 1993; Hayashi and Kondo, 2018). In the tracheal system, hemocytes exist alongside respiratory tubes and epithelia 
to assist with development (Hartenstein et al., 1994; Baer et al., 2010) and prevention of infection (Sanchez Bosch et al., 2019). Specifically, during embryonic development, tracheal cells at the base of the dorsal branch undergo apoptosis in response to microenvironmental cues, detach from the epithelium, and are engulfed by macrophages (Baer et al., 2010). Tracheal cells also undergo apoptosis as part of tracheal remodeling during metamorphosis, suggesting a possible role for phagocytosing macrophages at this stage of development (Chen and Krasnow, 2014). Following pupariation, macrophages of the embryonic lineage and dispersed lymph gland hemocytes (Holz et al., 2003; Grigorian et al., 2011) associate with the respiratory epithelia (air sacs) in the head and thorax of the adult animal, forming the major blood cell reservoir (Sanchez Bosch et al., 2019). Here, macrophages act as sentinels of infection, engulfing pathogens and instructing the respiratory epithelia and neighboring cells of the fat body via secretion of Upd3 to produce e.g., the AMP Drosocin (Tzou et al., 2000; Sanchez Bosch et al., 2019), which defends against bacterial infection (Lemaitre et al., 1995; Sanchez Bosch et al., 2019).

\section{FAT BODY}

The Drosophila fat body is a site of energy storage, detoxification and immune response that functionally parallels the vertebrate liver (Miller et al., 2002; Dionne, 2014). It forms an extensive tissue in the embryo and larva, and lines the majority of the adult cuticle and epidermis (Zhang and Xi, 2015). During larval development, macrophages contribute critically to basement membrane formation of the fat body via the deposition of SPARC, a glycoprotein involved in the assembly of collagen IV (Shahab et al., 2015). Later, during metamorphosis, larval fat body cells undergo remodeling, resulting in fat body dissociation and apoptosis (Nelliot et al., 2006; Sanchez Bosch et al., 2019). Macrophages associate with these decaying cells and are involved in the phagocytosis of the cellular debris, a process that lasts well into adulthood (Nelliot et al., 2006; Sanchez Bosch et al., 2019).

Macrophages affect many aspects of metabolic regulation, homeostasis and immunity in the fat body (Dionne, 2014). For example, when larvae are raised on a high fat diet, or exposed to parasitic wasp infestation, plasmatocytes produce excess Upd3, inducing Jak/Stat signaling in the fat body, which downregulates insulin production, decreases larval growth, and reduces lifespan (Woodcock et al., 2015; Shin et al., 2020). This mechanism is mirrored in animals on a high sucrose diet (Parupalli et al., 2020). In response to bacterial infection, hemocytes communicate to the fat body through signals including Upd3 and the Toll ligand Spätzle to induce AMP expression, in both the larva and adult (Agaisse et al., 2003; Brennan et al., 2007; Charroux and Royet, 2009; Shia et al., 2009; Honti et al., 2014; Sanchez Bosch et al., 2019). Bacterial infection also stimulates hemocytes to release ImpL2, an insulin/IGF antagonist, which induces the release of lipoproteins and carbohydrates from the fat body to fuel the immune response (Gabriela et al., 2020); in turn, hemocytes switch to aerobic glycolysis, which supports the antibacterial defense (Krejèová et al., 2019).
Conversely, fat body cells regulate hemocyte populations during instances of nutrient deprivation and immune challenge. During starvation, macrophages move from the hematopoietic pockets and other locations to infiltrate the larval fat body (Shim et al., 2012). Specifically, the fat body releases NimB5, which acts on hemocytes to downregulate adhesion and proliferation (Ramond et al., 2020b). This mechanism redirects resources to essential functions only, promoting animal survival (Ramond et al., 2020b). Under immune challenge such as parasitic wasp infestation, signals from the fat body promote hemocyte responses: Toll signaling in the fat body promotes the Toll-dependent activation of macrophages (Schmid et al., 2014). Moreover, fat body cells upregulate expression of Edin (elevated during infection), a secreted peptide that promotes an increase in macrophage number and also triggers their release from the hematopoietic pockets and other resident locations, thereby facilitating the encapsulation response (Vanha-aho et al., 2015).

\section{MUSCLE SYSTEM}

Drosophila has a complex muscle system at all stages of development (Bothe and Baylies, 2016). Macrophages and the muscular system form another axis of communication in Drosophila. In the adult animal, under non-inflammatory physiology, hemocytes constitutively produce Upd3, which promotes basal JAK/STAT activity in muscle cells (Kierdorf et al., 2020). When disrupting this signaling by loss of the dome receptor in muscles, a systemic metabolic pathology develops, characterized by hyperactivation of the kinase AKT, an insulin signaling mediator, and reduced lifespan (Kierdorf et al., 2020). While this study raises new interesting questions, the interactions between muscle, insulin signaling, metabolism, and growth have been an intense focus of investigation (Demontis and Perrimon, 2009, 2010; Kwon et al., 2015).

Molecular communication in both directions, including signaling from the muscles to macrophages, is central in establishing immune responses (Yang et al., 2015; Yang and Hultmark, 2017). In the Drosophila larva, muscles regulate plasmatocytes in the immune response to parasitic wasp infestation. This effect is initially triggered by the release of Upd2 and Upd3 from plasmatocytes during wasp infestation, activating the JAK/STAT pathway in muscle tissue beyond basal levels (Yang et al., 2015; Shin et al., 2020). In turn, muscle cells control the plasmatocyte response, promoting the number of plasmatocytederived lamellocytes and enhancing the encapsulation response (Yang et al., 2015). This effect appears to depend on altered feeding behavior and is mediated by insulin signaling via TOR (target of rapamycin) in the muscles, which indirectly enhances JAK/STAT signaling in hemocytes, driving lamellocyte formation (Yang et al., 2015; Anderl et al., 2016; Yang and Hultmark, 2017). Interestingly, larval muscles are an anatomical part of the hematopoietic pockets where plasmatocytes reside in clusters, suggesting that muscle cells are an active player of this instructive microenvironment (Makhijani et al., 2011; Makhijani and Brückner, 2012; Yang et al., 2015). 


\section{HEART}

In Drosophila and in insects in general, macrophages accumulate in clusters at the ostia (intake valves) of the heart (Gupta, 1979), a tubular structure running along the dorsal side of the animal (Ocorr et al., 2007). Macrophages in these clusters monitor the streaming hemolymph of the open circulatory system and fulfill immune functions, phagocytosing bacteria and foreign particles (Gupta, 1979; Elrod-Erickson et al., 2000; Dionne et al., 2003; King and Hillyer, 2012; Cevik et al., 2019). Relatively little is known about interactions between macrophages and heart tissue. In Drosophila third instar larvae, hemocytes from resident sites increasingly enter circulation and subsequently accumulate in clusters at the ostia and pericardial nephrocytes of the larval heart (dorsal vessel) (Frasch, 1999), forming dorsal vessel-associated clusters (Markus et al., 2009; Makhijani et al., 2011; Petraki et al., 2015; Cevik et al., 2019). Hemocytes accumulate in the ECM of the dorsal vessel, which is facilitated by the heart-specific collagen Pericardin (Cevik et al., 2019). In addition, some aspects of this accumulation may be mechanical (Petraki et al., 2015; Cevik et al., 2019). In adult Drosophila, hemocytes accumulate at the ostia of the heart in a mesh of ECM that likewise contains Pericardin and Laminin A (Ghosh et al., 2015; Sessions et al., 2017). One study suggested that the heart serves as a 'hematopoietic hub' for new hemocyte production (Ghosh et al., 2015), however, this model was disproven based on evidence of a developmental mechanism of macrophage accumulation at the heart, and the absence of any significant hematopoietic activity using multiple orthogonal approaches (Sanchez Bosch et al., 2019).

\section{RENAL TUBULES}

Drosophila Malpighian tubules (renal tubules) are excretory organs with similarity to the vertebrate kidney; they secrete waste and maintain ionic and osmotic homeostasis (Maddrell, 1972; Denholm and Skaer, 2009). During the embryonic development of the Malpighian tubules, macrophages are attracted to these growing structures through tubule expression of PVF ligands (Bunt et al., 2010). Macrophages, in turn, secrete components of the basement membrane (Bunt et al., 2010). Collagen IV is part of this, sensitizing tubule cells to the BMP ligand Dpp, which is required to promote the outgrowth of the tubules (Bunt et al., 2010). While it is known that Dpp is secreted locally, the source remains unknown; however, in the gut, Dpp is sourced from hemocytes (Guo et al., 2013; Ayyaz et al., 2015) and hemocytes could have a similar function for the Malpighian tubules. The process of macrophage-mediated tubule elongation is conserved in mice where tissue-resident macrophages contribute to renal organogenesis (Munro and Hughes, 2017).

\section{IMAGINAL DISCS}

Imaginal discs are the larval precursors to the adult fly eyes, wings, legs, and other appendages (Worley et al., 2012). They develop as epithelial sacs, which serve as intriguing models to study patterning, morphogenesis, and regeneration (Hariharan and Serras, 2017). Imaginal disc damage stimulates increase in macrophages that adhere to the wound (Bryant and Fraser, 1988; McClure et al., 2008; Pastor-Pareja et al., 2008; Katsuyama and Paro, 2013). In response to UV damage to the eye imaginal disc, macrophages actively promote tissue regeneration (Kelsey et al., 2012). Specifically, damaged disc cells upregulate Shnurri (Shn), a transcriptional regulator that induces $P v f 1$, which then signals to disc-associated hemocytes to activate their macrophagelike behavior (Kelsey et al., 2012). Activated hemocytes engulf apoptotic cells in the eye disc and clear debris to limit tissue damage (Kelsey et al., 2012). The activation of macrophages in this model relies at least in part on the induction of mesencephalic astrocyte-derived neurotrophic factor (MANF) (Neves et al., 2016). MANF shifts the expression of hemocyte markers and induces expression of the Drosophila homolog of the mammalian M2 marker arginase1, suggesting a process similar to the alternative activation of macrophages in vertebrates (Neves et al., 2016). Importantly, PDGF/MANF signaling of macrophages in response to retinal damage is conserved in mammals (Neves et al., 2016). Hemocytes also trigger tissue regeneration via epithelial cell proliferation in response to reactive oxygen species (ROSs) released from damaged epithelial disc cells (Fogarty et al., 2016). In a model of apoptosis-induced proliferation (AiP), in which eye disc cells were induced to die by the pro-apoptotic gene head involution defect (hid), while apoptosis was concomitantly blocked by p35 (Ryoo et al., 2004), activity of the caspase Dronc in epithelial disc cells promotes activation of the NADPH oxidase Duox that generates extracellular ROSs (Fogarty et al., 2016). ROS release activates disc-associated macrophages and induces them to secrete the TNF (tumor necrosis factor) family ligand Eiger, which activates JNK signaling in disc cells leading to proliferation (Fogarty et al., 2016). Similar mechanisms of ROS-induced JNK signaling may apply to the regeneration of damaged wing discs, although the role of hemocytes in this context remains to be investigated (Santabárbara-Ruiz et al., 2015). One study reported hemocytes to be dispensable for the regenerative growth of aseptic wounds of wing discs or transplanted leg disc fragments under conditions of combined ablation of hemocytes and fat body (Katsuyama and Paro, 2013). However, these experiments were performed in developmentally arrested larvae fed with $\operatorname{erg} 2 \Delta$ mutant yeast (Katsuyama and Paro, 2013) that does not provide sterols necessary for the formation of the fly hormone ecdysone (Parkin and Burnet, 1986). Ecdysone controls molting, but also stimulates hemocyte phagocytic activity and mobility, and the encapsulation response (Sorrentino et al., 2002; Regan et al., 2013; Sampson et al., 2013), which could have affected experimental outcomes (Katsuyama and Paro, 2013).

\section{DISCUSSION}

Drosophila and vertebrates share many parallels in their macrophage systems, which in both cases are based on two lineages. While the anatomical origins of tissue macrophages in Drosophila and vertebrates differ, there are many evolutionary 
parallels at the molecular, cellular, and functional level. Considering that this lineage is the predominant source of macrophages in Drosophila (Sanchez Bosch et al., 2019), we propose that tissue macrophages may represent the ancient mechanism of macrophage production and regulation, allowing immediate adaptation to organismal and environmental conditions. This may be particularly important in species that heavily rely on innate immunity.

The diverse functional roles of Drosophila macrophages predict defined subpopulations, influenced by local signals from their tissue of residence, and possibly lineage and other conditions. This resembles vertebrates, in which macrophage populations have been characterized based on their polarization, i.e., their distinct functional phenotypes, regulated by microenvironmental and systemic stimuli (Gordon and Taylor, 2005; Martinez, 2008; Lavin et al., 2015; Zhu et al., 2015; Shapouri-Moghaddam et al., 2018). Vertebrate macrophages exhibit functional plasticity to differentiate into classically activated macrophages (M1) with roles in infection, and alternatively activated macrophages (M2) active in tissue repair and anti-inflammatory responses; further subdivisions are based on their prototypical activating stimuli and functionality (Martinez, 2008; Tarique et al., 2015; Zhu et al., 2015; ShapouriMoghaddam et al., 2018). Recent analyses suggest an even greater spectrum of activation states exceeding these classifications (Mosser and Edwards, 2008; Xue et al., 2014), and lineage also plays a role in determining the properties and activation states of macrophages (Gundra et al., 2014). Macrophages may adopt potentially distinct activation states when mediating previously unknown functions, such as the transfer of mitochondria to and from target tissues including neurons and heart cells, which promotes repair after tissue damage, and stimulates the macrophage innate immune response, respectively (Jackson et al., 2016; Brestoff et al., 2020; Nicolás-Ávila et al., 2020; Raoof et al., 2020).

Research in Drosophila suggests that the characteristics of macrophages are changed following priming by an immune encounter, such as phagocytosis of apoptotic cells (Weavers et al., 2016; Nonaka et al., 2017; Roddie et al., 2019; Chakrabarti and Visweswariah, 2020). This interaction leads to "immune training", consisting of changes in intracellular signaling and the repertoire of phagocytic receptors, which can determine behavior in future encounters (Weavers et al., 2016; Nonaka et al., 2017; Roddie et al., 2019; Chakrabarti and Visweswariah, 2020). Consistent with this, a study provided molecular evidence of Drosophila macrophages taking on an alternatively activated (M2) status in response to local cues in tissue regeneration (Neves et al., 2016). Single cell RNA sequencing and functional studies

\section{REFERENCES}

Abrams, J. M., White, K., Fessler, L. I., and Steller, H. (1993). Programmed cell death during Drosophila embryogenesis. Development 117, 29-43.

Agaisse, H., Petersen, U. M., Boutros, M., Mathey-Prevot, B., and Perrimon, N. (2003). Signaling role of hemocytes in Drosophila JAK/STAT-dependent response to septic injury. Dev. Cell 5, 441-450. doi: 10.1016/s1534-5807(03) 00244- 2 further support the hypothesis of distinct activation states in Drosophila macrophages, identifying subpopulations that have differential involvement in phagocytosis, metabolic homeostasis, and the humoral AMP response (Cattenoz et al., 2020; Cho et al., 2020; Coates et al., 2020; Fu et al., 2020; Ramond et al., 2020a; Shin et al., 2020; Tattikota et al., 2020). Functional distinctions are driven by developmental stage (Cattenoz et al., 2020; Cho et al., 2020), injury, and immune challenge (Coates et al., 2020; Fu et al., 2020; Ramond et al., 2020a; Tattikota et al., 2020).

Additional research will link many of the observed cellular differences between macrophage populations with their roles in specific organ systems, as exemplified in this review. A particular gap in knowledge is how microenvironmental cues shape the molecular and phenotypic status of macrophages to adapt to their distinct tasks, and how interactions between immune cell types and lineages may affect their response. In vertebrates, organ microenvironments regulate tissue macrophages through local production of CSF1, IL-34, and paracrine and autocrine TGF- $\beta$ (Lavin et al., 2015). However, findings from Drosophila (Makhijani et al., 2011, 2017; Gold and Brückner, 2014, 2015; Corcoran et al., 2020) suggest the existence of more elaborate regulatory systems also in vertebrates, comprising, e.g., peripheral innervation or cell based environmental sensors that regulate local tissue macrophage populations through molecular signals. Understanding cellular and molecular principles of organmacrophage communication in Drosophila will further broaden our insights into vertebrate macrophage systems, and contribute to approaches that harness the power of macrophages in regenerative medicine and immunology.

\section{AUTHOR CONTRIBUTIONS}

$\mathrm{AM}$ and JA wrote the text and designed the figures. $\mathrm{KB}$ revised the text and figures, designed figure elements, and coordinated the content of the review. All authors contributed to the article and approved the submitted version.

\section{FUNDING}

This work was supported by grants from the National Institutes of Health 1R01GM112083 and 1R01GM131094 (to KB).

\section{ACKNOWLEDGMENTS}

We apologize to authors whose work was not cited due to space constraints or accidental oversight.

Ajami, B., Bennett, J. L., Krieger, C., Tetzlaff, W., and Rossi, F. M. V. (2007). Local self-renewal can sustain CNS microglia maintenance and function throughout adult life. Nat. Neurosci. 10, 1538-1543. doi: 10.1038/nn2014

Akin, O., and Zipursky, S. L. (2020). Activity regulates brain development in the fly. Curr. Opin. Genet. Dev. 65, 8-13. doi: 10.1016/j.gde.2020.04.005

Alfonso, T. B., and Jones, B. W. (2002). gcm2 promotes glial cell differentiation and is required with glial cells missing for macrophage development in Drosophila. Dev. Biol. 248, 369-383. doi: 10.1006/dbio.2002.0740 
Anderl, I., Vesala, L., Ihalainen, T. O., Vanha-aho, L.-M., Andó, I., Rämet, M., et al. (2016). Transdifferentiation and proliferation in two distinct hemocyte lineages in Drosophila melanogaster Larvae after Wasp infection. PLoS Pathog. 12:e1005746. doi: 10.1371/journal.ppat.1005746

Arefin, B., Kucerova, L., Krautz, R., Kranenburg, H., Parvin, F., and Theopold, U. (2015). Apoptosis in hemocytes induces a shift in effector mechanisms in the Drosophila immune system and leads to a pro-inflammatory state. PLoS One 10:e0136593. doi: 10.1371/journal.pone.0136593

Ayyaz, A., Li, H., and Jasper, H. (2015). Haemocytes control stem cell activity in the Drosophila intestine. Nat. Cell Biol. 17, 736-748. doi: 10.1038/ncb 3174

Babcock, D. T., Brock, A. R., Fish, G. S., Wang, Y., Perrin, L., Krasnow, M. A., et al. (2008). Circulating blood cells function as a surveillance system for damaged tissue in Drosophila larvae. Proc. Natl. Acad. Sci. U.S.A. 105, 10017-10022. doi: 10.1073/pnas.0709951105

Baer, M. M., Bilstein, A., Caussinus, E., Csiszar, A., Affolter, M., and Leptin, M. (2010). The role of apoptosis in shaping the tracheal system in the Drosophila embryo. Mech. Dev. 127, 28-35. doi: 10.1016/j.mod.2009.11.003

Banerjee, U., Girard, J. R., Goins, L. M., and Spratford, C. M. (2019). Drosophila as a genetic model for hematopoiesis. Genetics 211, 367-417. doi: 10.1534/genetics. 118.300223

Bernardoni, R., Vivancos, V., and Giangrande, A. (1997). glide/gcm is expressed and required in the scavenger cell lineage. Dev. Biol. 191, 118-130. doi: 10.1006/ dbio.1997.8702

Bittern, J., Pogodalla, N., Ohm, H., Brüser, L., Kottmeier, R., Schirmeier, S., et al. (2020). Neuron-glia interaction in the Drosophila nervous system. Dev. Neurobiol. doi: 10.1002/dneu.22737 [Epub ahead of print].

Bonfini, A., Liu, X., and Buchon, N. (2016). From pathogens to microbiota: how Drosophila intestinal stem cells react to gut microbes. Dev. Comp. Immunol. 64, 22-38. doi: 10.1016/j.dci.2016.02.008

Bothe, I., and Baylies, M. K. (2016). Drosophila myogenesis. Curr. Biol. 26, R786R791. doi: 10.1016/j.cub.2016.07.062

Braun, A., Hoffmann, J. A., and Meister, M. (1998). Analysis of the Drosophila host defense in domino mutant larvae, which are devoid of hemocytes. Proc. Natl. Acad. Sci. U.S.A. 95, 14337-14342. doi: 10.1073/pnas.95.24.14337

Brennan, C. A., Delaney, J. R., Schneider, D. S., and Anderson, K. V. (2007). Psidin is required in Drosophila blood cells for both phagocytic degradation and immune activation of the fat body. Curr. Biol. 17, 67-72. doi: 10.1016/j. cub.2006.11.026

Brestoff, J. R., Wilen, C. B., Moley, J. R., Li, Y., Zou, W., Malvin, N. P., et al. (2020). Intercellular mitochondria transfer to macrophages regulates white adipose tissue homeostasis and is impaired in obesity. Cell Metab. doi: 10.1016/j.cmet. 2020.11.008 [Epub ahead of print].

Bretscher, A. J., Honti, V., Binggeli, O., Burri, O., Poidevin, M., Kurucz, E., et al. (2015). The Nimrod transmembrane receptor Eater is required for hemocyte attachment to the sessile compartment in Drosophila melanogaster. Biol. Open 4, 355-363. doi: 10.1242/bio.201410595

Brückner, K., Kockel, L., Duchek, P., Luque, C. M., Rørth, P., and Perrimon, N. (2004). The PDGF/VEGF receptor controls blood cell survival in Drosophila. Dev. Cell 7, 73-84. doi: 10.1016/j.devcel.2004.06.007

Bryant, P. J., and Fraser, S. E. (1988). Wound healing, cell communication, and DNA synthesis during imaginal disc regeneration in Drosophila. Dev. Biol. 127, 197-208. doi: 10.1016/0012-1606(88)90201-1

Buchon, N., Silverman, N., and Cherry, S. (2014). Immunity in Drosophila melanogaster - from microbial recognition to whole-organism physiology. Nat. Rev. Immunol. 14, 796-810. doi: 10.1038/nri3763

Bunt, S., Hooley, C., Hu, N., Scahill, C., Weavers, H., and Skaer, H. (2010). Hemocyte-secreted Type IV collagen enhances BMP signaling to guide renal tubule morphogenesis in Drosophila. Dev. Cell 19, 296-306. doi: 10.1016/j. devcel.2010.07.019

Cattenoz, P. B., Sakr, R., Pavlidaki, A., Delaporte, C., Riba, A., Molina, N., et al. (2020). Temporal specificity and heterogeneity of Drosophila immune cells. EMBO J. 39:e104486. doi: 10.15252/embj.2020104486

Cevik, D., Acker, M., Michalski, C., and Jacobs, J. R. (2019). Pericardin, a Drosophila collagen, facilitates accumulation of hemocytes at the heart. Dev. Biol. 454, 52-65. doi: 10.1016/j.ydbio.2019.06.006

Chakrabarti, S., Dudzic, J. P., Li, X., Collas, E. J., Boquete, J.-P., and Lemaitre, B. (2016). Remote control of intestinal stem cell activity by haemocytes in Drosophila. PLoS Genet. 12:e1006089. doi: 10.1371/journal.pgen.1006089
Chakrabarti, S., and Visweswariah, S. S. (2020). Intramacrophage ROS primes the innate immune system via JAK/STAT and toll activation. Cell Rep. 33:108368. doi: $10.1016 /$ j.celrep.2020.108368

Charroux, B., and Royet, J. (2009). Elimination of plasmatocytes by targeted apoptosis reveals their role in multiple aspects of the Drosophila immune response. Proc. Natl. Acad. Sci. U.S.A. 106, 9797-9802. doi: 10.1073/pnas. 0903971106

Chen, F., and Krasnow, M. A. (2014). Progenitor outgrowth from the niche in Drosophila trachea is guided by FGF from decaying branches. Science 343, 186-189. doi: 10.1126/science.1241442

Cho, B., Yoon, S.-H., Lee, D., Koranteng, F., Tattikota, S. G., Cha, N., et al. (2020). Single-cell transcriptome maps of myeloid blood cell lineages in Drosophila. Nat. Commun. 11:4483. doi: 10.1038/s41467-020-18135-y

Coates, J. A., Brittle, A., Armitage, E. L., Zeidler, M. P., and Evans, I. R. (2020). Identification of functionally-distinct macrophage subpopulations regulated by efferocytosis in Drosophila. Dev. Biol. doi: 10.1101/2020.04.17.047472 [Epub ahead of print].

Cognigni, P., Bailey, A. P., and Miguel-Aliaga, I. (2011). Enteric neurons and systemic signals couple nutritional and reproductive status with intestinal homeostasis. Cell Metab. 13, 92-104. doi: 10.1016/j.cmet.2010.12.010

Cohen, P. E., Zhu, L., and Pollard, J. W. (1997). Absence of colony stimulating factor-1 in osteopetrotic (csfmop/csfmop) mice disrupts estrous cycles and ovulation. Biol. Reprod. 56, 110-118. doi: 10.1095/biolreprod56.1.110

Corcoran, S., Mase, A., Hashimi, Y., Ouyang, D., Augsburger, J., Jacobs, T., et al. (2020). Regulation of blood cell transdifferentiation by oxygen sensing neurons in Drosophila. bioRxiv [Preprint] doi: 10.1101/2020.04.22.056622

Crozatier, M., Ubeda, J.-M., Vincent, A., and Meister, M. (2004). Cellular immune response to parasitization in Drosophila requires the EBF orthologue collier. PLoS Biol. 2:e196. doi: 10.1371/journal.pbio.0020196

Csordás, G., Grawe, F., and Uhlirova, M. (2020). Eater cooperates with Multiplexin to drive the formation of hematopoietic compartments. eLife 9:e57297. doi: 10.7554/eLife. 57297

Davidson, A. J., and Wood, W. (2020). Phagocyte responses to cell death in flies. Cold Spring Harb. Perspect. Biol. 12:a036350. doi: 10.1101/cshperspect.a036350

Davies, L. C., Jenkins, S. J., Allen, J. E., and Taylor, P. R. (2013). Tissue-resident macrophages. Nat. Immunol. 14, 986-995. doi: 10.1038/ni.2705

Defaye, A., Evans, I., Crozatier, M., Wood, W., Lemaitre, B., and Leulier, F. (2009). Genetic ablation of Drosophila phagocytes reveals their contribution to both development and resistance to bacterial infection. J. Innate Immun. 1, 322-334. doi: $10.1159 / 000210264$

Demontis, F., and Perrimon, N. (2009). Integration of Insulin receptor/Foxo signaling and dMyc activity during muscle growth regulates body size in Drosophila. Development 136, 983-993. doi: 10.1242/dev.027466

Demontis, F., and Perrimon, N. (2010). FOXO/4E-BP signaling in Drosophila muscles regulates organism-wide proteostasis during aging. Cell 143, 813-825. doi: 10.1016/j.cell.2010.10.007

Denef, N., Chen, Y., Weeks, S. D., Barcelo, G., and Schüpbach, T. (2008). Crag regulates epithelial architecture and polarized deposition of basement membrane proteins in Drosophila. Dev. Cell 14, 354-364. doi: 10.1016/j.devcel. 2007.12.012

Denholm, B., and Skaer, H. (2009). Bringing together components of the fly renal system. Curr. Opin. Genet. Dev. 19, 526-532. doi: 10.1016/j.gde.2009.08.006

Destalminil-Letourneau, M., Morin-Poulard, I., Tian, Y., Vanzo, N., and Crozatier, M. (2021). The vascular niche controls Drosophila hematopoiesis via fibroblast growth factor signaling. eLife 10:64672. doi: 10.7554/eLife.64672

Dionne, M. (2014). Immune-metabolic interaction in Drosophila. Fly (Austin) 8, 75-79. doi: 10.4161/fly.28113

Dionne, M. S., Ghori, N., and Schneider, D. S. (2003). Drosophila melanogaster is a genetically tractable model host for Mycobacterium marinum. Infect. Immun. 71, 3540-3550. doi: 10.1128/iai.71.6.3540-3550.2003

Doe, C. Q. (2017). Temporal patterning in the Drosophila CNS. Annu. Rev. Cell Dev. Biol. 33, 219-240. doi: 10.1146/annurev-cellbio-111315-125210

Dragojlovic-Munther, M., and Martinez-Agosto, J. A. (2013). Extracellular matrixmodulated Heartless signaling in Drosophila blood progenitors regulates their differentiation via a Ras/ETS/FOG pathway and target of rapamycin function. Dev. Biol. 384, 313-330. doi: 10.1016/j.ydbio.2013.04.004

Dzierzak, E., and Speck, N. A. (2008). Of lineage and legacy: the development of mammalian hematopoietic stem cells. Nat. Immunol. 9, 129-136. doi: 10.1038/ ni1560 
Elrod-Erickson, M., Mishra, S., and Schneider, D. (2000). Interactions between the cellular and humoral immune responses in Drosophila. Curr. Biol. 10, 781-784. doi: 10.1016/s0960-9822(00)00569-8

Evans, I. R., Hu, N., Skaer, H., and Wood, W. (2010). Interdependence of macrophage migration and ventral nerve cord development in Drosophila embryos. Development 137, 1625-1633. doi: 10.1242/dev.046797

Evans, I. R., Rodrigues, F. S. L. M., Armitage, E. L., and Wood, W. (2015). Draper/CED-1 mediates an ancient damage response to control inflammatory blood cell migration in vivo. Curr. Biol. 25, 1606-1612. doi: 10.1016/j.cub.2015. 04.037

Ferguson, G. B., and Martinez-Agosto, J. A. (2014). Yorkie and scalloped signaling regulates notch-dependent lineage specification during Drosophila hematopoiesis. Curr. Biol. 24, 2665-2672. doi: 10.1016/j.cub.2014.09.081

Fessler, J. H., and Fessler, L. I. (1989). Drosophila extracellular matrix. Annu. Rev. Cell. Biol. 5, 309-339. doi: 10.1146/annurev.cb.05.110189.001521

Fogarty, C. E., Diwanji, N., Lindblad, J. L., Tare, M., Amcheslavsky, A., Makhijani, K., et al. (2016). Extracellular reactive oxygen species drive apoptosis-induced proliferation via Drosophila macrophages. Curr. Biol. 26, 575-584. doi: 10.1016/ j.cub.2015.12.064

Frame, J. M., McGrath, K. E., and Palis, J. (2013). Erythro-myeloid progenitors: "Definitive" hematopoiesis in the conceptus prior to the emergence of hematopoietic stem cells. Blood Cells Mol. Dis. 51, 220-225. doi: 10.1016/j. bcmd.2013.09.006

Franc, N. C. (1999). Requirement for croquemort in phagocytosis of apoptotic cells in Drosophila. Science 284, 1991-1994. doi: 10.1126/science.284.5422.1991

Frasch, M. (1999). Intersecting signalling and transcriptional pathways in Drosophila heart specification. Semin. Cell Dev. Biol. 10, 61-71. doi: 10.1006/ scdb.1998.0279

Fu, Y., Huang, X., Zhang, P., van de Leemput, J., and Han, Z. (2020). Singlecell RNA sequencing identifies novel cell types in Drosophila blood. J. Genet. Genomics 47, 175-186. doi: 10.1016/j.jgg.2020.02.004

Fuller, M. T., and Spradling, A. C. (2007). Male and female Drosophila germline stem cells: two versions of immortality. Science 316, 402-404. doi: 10.1126/ science. 1140861

Furusawa, K., and Emoto, K. (2020). Spatiotemporal regulation of developmental neurite pruning: molecular and cellular insights from Drosophila models. Neurosci. Res. doi: 10.1016/j.neures.2020.11.010 [Epub ahead of print].

Gabriela, K., Adam, B., Pavla, N., Julie, K., Nick, K.-H., Helena, Z., et al. (2020). Macrophage-derived insulin/IGF antagonist ImpL2 regulates systemic metabolism for mounting an effective acute immune response in Drosophila. bioRxiv [Preprint] doi: 10.1101/2020.09.24.311670

Geissmann, F., Manz, M. G., Jung, S., Sieweke, M. H., Merad, M., and Ley, K. (2010). Development of monocytes, macrophages, and dendritic cells. Science 327, 656-661. doi: 10.1126/science.1178331

Ghosh, S., Singh, A., Mandal, S., and Mandal, L. (2015). Active hematopoietic hubs in Drosophila adults generate hemocytes and contribute to immune response. Dev. Cell 33, 478-488. doi: 10.1016/j.devcel.2015.03.014

Ginhoux, F., Schultze, J. L., Murray, P. J., Ochando, J., and Biswas, S. K. (2016). New insights into the multidimensional concept of macrophage ontogeny, activation and function. Nat. Immunol. 17, 34-40. doi: 10.1038/ni.3324

Gold, K. S., and Brückner, K. (2014). Drosophila as a model for the two myeloid blood cell systems in vertebrates. Exp. Hematol. 42, 717-727. doi: 10.1016/j. exphem.2014.06.002

Gold, K. S., and Brückner, K. (2015). Macrophages and cellular immunity in Drosophila melanogaster. Semin. Immunol. 27, 357-368. doi: 10.1016/j.smim. 2016.03.010

Gomez Perdiguero, E., Klapproth, K., Schulz, C., Busch, K., Azzoni, E., Crozet, L., et al. (2015). Tissue-resident macrophages originate from yolk-sac-derived erythro-myeloid progenitors. Nature 518, 547-551. doi: 10.1038/nature13989

Gordon, S., and Taylor, P. R. (2005). Monocyte and macrophage heterogeneity. Nat. Rev. Immunol. 5, 953-964. doi: 10.1038/nri1733

Gosselin, D., Link, V. M., Romanoski, C. E., Fonseca, G. J., Eichenfield, D. Z., Spann, N. J., et al. (2014). Environment drives selection and function of enhancers controlling tissue-specific macrophage identities. Cell 159, 13271340. doi: 10.1016/j.cell.2014.11.023

Grigorian, M., Mandal, L., and Hartenstein, V. (2011). Hematopoiesis at the onset of metamorphosis: terminal differentiation and dissociation of the Drosophila lymph gland. Dev. Genes Evol. 221, 121-131. doi: 10.1007/s00427-011-0364-6
Guillou, A., Troha, K., Wang, H., Franc, N. C., and Buchon, N. (2016). The Drosophila CD36 homologue croquemort is required to maintain immune and gut homeostasis during development and aging. PLoS Pathog. 12:e1005961. doi: 10.1371/journal.ppat.1005961

Gundra, U. M., Girgis, N. M., Ruckerl, D., Jenkins, S., Ward, L. N., Kurtz, Z. D., et al. (2014). Alternatively activated macrophages derived from monocytes and tissue macrophages are phenotypically and functionally distinct. Blood 123, e110-e122. doi: 10.1182/blood-2013-08-520619

Guo, Z., Driver, I., and Ohlstein, B. (2013). Injury-induced BMP signaling negatively regulates Drosophila midgut homeostasis. J. Cell Biol. 201, 945-961. doi: $10.1083 /$ jcb.201302049

Gupta, A. P. (1979). Insect Hemocytes: Development, Forms, Functions, and Techniques. New York, NY: Cambridge University Press.

Han, C., Song, Y., Xiao, H., Wang, D., Franc, N. C., Jan, L. Y., et al. (2014). Epidermal cells are the primary phagocytes in the fragmentation and clearance of degenerating dendrites in Drosophila. Neuron 81, 544-560. doi: 10.1016/j. neuron.2013.11.021

Hariharan, I. K., and Serras, F. (2017). Imaginal disc regeneration takes flight. Curr. Opin. Cell Biol. 48, 10-16. doi: 10.1016/j.ceb.2017.03.005

Hartenstein, V. (1995). Atlas of Drosophila Development, 1 Edn. Cold Spring Harbor, NY: Cold Spring Harbor Laboratory Press.

Hartenstein, V. (2006). Blood cells and blood cell development in the animal kingdom. Annu. Rev. Cell Dev. Biol. 22, 677-712. doi: 10.1146/annurev.cellbio. 22.010605.093317

Hartenstein, V., Spindler, S., Pereanu, W., and Fung, S. (2008). "The development of the Drosophila larval brain," in Brain Development in Drosophila melanogaster Advances in Experimental Medicine and Biology, ed. G. M. Technau (New York, NY: Springer New York), 1-31. doi: 10.1007/978-0-38778261-4_1

Hartenstein, V., Tepass, U., and Gruszynski-Defeo, E. (1994). Embryonic development of the stomatogastric nervous system in Drosophila. J. Comp. Neurol. 350, 367-381. doi: 10.1002/cne.903500304

Hashimoto, D., Chow, A., Noizat, C., Teo, P., Beasley, M. B., Leboeuf, M., et al. (2013). Tissue-resident macrophages self-maintain locally throughout adult life with minimal contribution from circulating monocytes. Immunity 38, 792-804. doi: 10.1016/j.immuni.2013.04.004

Hayashi, S., and Kondo, T. (2018). Development and function of the Drosophila tracheal system. Genetics 209, 367-380. doi: 10.1534/genetics.117.300167

Herbomel, P., Thisse, B., and Thisse, C. (2001). Zebrafish early macrophages colonize cephalic mesenchyme and developing brain, retina, and epidermis through a M-CSF receptor-dependent invasive process. Dev. Biol. 238, 274-288. doi: 10.1006/dbio.2001.0393

Hidalgo, A., Kinrade, E. F. V., and Georgiou, M. (2001). The Drosophila neuregulin vein maintains glial survival during axon guidance in the CNS. Dev. Cell 1, 679-690. doi: 10.1016/S1534-5807(01)00074-0

Hilu-Dadia, R., and Kurant, E. (2020). Glial phagocytosis in developing and mature Drosophila CNS: tight regulation for a healthy brain. Curr. Opin. Immunol. 62, 62-68. doi: 10.1016/j.coi.2019.11.010

Hoeffel, G., Wang, Y., Greter, M., See, P., Teo, P., Malleret, B., et al. (2012). Adult Langerhans cells derive predominantly from embryonic fetal liver monocytes with a minor contribution of yolk sac-derived macrophages. J. Exp. Med. 209, 1167-1181. doi: 10.1084/jem.20120340

Holz, A., Bossinger, B., Strasser, T., Janning, W., and Klapper, R. (2003). The two origins of hemocytes in Drosophila. Development 130, 4955-4962. doi: 10.1242/ dev.00702

Honti, V., Csordás, G., Kurucz, É, Márkus, R., and Andó, I. (2014). The cellmediated immunity of Drosophila melanogaster: hemocyte lineages, immune compartments, microanatomy and regulation. Dev. Comp. Immunol. 42, 47-56. doi: 10.1016/j.dci.2013.06.005

Horn, L., Leips, J., and Starz-Gaiano, M. (2014). Phagocytic ability declines with age in adult Drosophila hemocytes. Aging Cell 13, 719-728. doi: 10.1111/acel.12227

Hughes, C. L., and Thomas, J. B. (2007). A sensory feedback circuit coordinates muscle activity in Drosophila. Mol. Cell Neurosci. 35, 383-396. doi: 10.1016/j. mcn.2007.04.001

Jackson, M. V., Morrison, T. J., Doherty, D. F., McAuley, D. F., Matthay, M. A., Kissenpfennig, A., et al. (2016). Mitochondrial transfer via tunneling nanotubes is an important mechanism by which mesenchymal stem cells enhance macrophage phagocytosis in the in vitro and in vivo models of ARDS: 
mitochondrial transfer from MSC to macrophages. Stem Cells 34, 2210-2223. doi: $10.1002 /$ stem. 2372

Jiang, H., Patel, P. H., Kohlmaier, A., Grenley, M. O., McEwen, D. G., and Edgar, B. A. (2009). Cytokine/Jak/Stat signaling mediates regeneration and homeostasis in the Drosophila midgut. Cell 137, 1343-1355. doi: 10.1016/j.cell. 2009.05.014

Jung, S.-H. (2005). The Drosophila lymph gland as a developmental model of hematopoiesis. Development 132, 2521-2533. doi: 10.1242/dev.01837

Karcavich, R., and Doe, C. Q. (2005). Drosophila neuroblast 7-3 cell lineage: a model system for studying programmed cell death, Notch/Numb signaling, and sequential specification of ganglion mother cell identity. J. Comp. Neurol. 481, 240-251. doi: 10.1002/cne.20371

Katsuyama, T., and Paro, R. (2013). Innate immune cells are dispensable for regenerative growth of imaginal discs. Mech. Dev. 130, 112-121. doi: 10.1016/j. mod.2012.11.005

Kelsey, E. M., Luo, X., Bruckner, K., and Jasper, H. (2012). Schnurri regulates hemocyte function to promote tissue recovery after DNA damage. J. Cell Sci. 125, 1393-1400. doi: 10.1242/jcs.095323

Kierdorf, K., Hersperger, F., Sharrock, J., Vincent, C. M., Ustaoglu, P., Dou, J., et al. (2020). Muscle function and homeostasis require cytokine inhibition of AKT activity in Drosophila. eLife 9:e51595. doi: 10.7554/eLife.51595

King, J. G., and Hillyer, J. F. (2012). Infection-induced interaction between the mosquito circulatory and immune systems. PLoS Pathog. 8:e1003058. doi: 10. 1371/journal.ppat.1003058

Kocks, C., Cho, J. H., Nehme, N., Ulvila, J., Pearson, A. M., Meister, M., et al. (2005). Eater, a transmembrane protein mediating phagocytosis of bacterial pathogens in Drosophila. Cell 123, 335-346. doi: 10.1016/j.cell.2005.08.034

Koh, T. J., and DiPietro, L. A. (2011). Inflammation and wound healing: the role of the macrophage. Expert Rev. Mol. Med. 13, e23. doi: 10.1017/ S1462399411001943

Krejèová, G., Danielová, A., Nedbalová, P., Kazek, M., Strych, L., Chawla, G., et al. (2019). Drosophila macrophages switch to aerobic glycolysis to mount effective antibacterial defense. eLife 8:e50414. doi: 10.7554/eLife.50414

Krzemien, J., Crozatier, M., and Vincent, A. (2010a). Ontogeny of the Drosophila larval hematopoietic organ, hemocyte homeostasis and the dedicated cellular immune response to parasitism. Int. J. Dev. Biol. 54, 1117-1125. doi: 10.1387/ ijdb.093053jk

Krzemien, J., Oyallon, J., Crozatier, M., and Vincent, A. (2010b). Hematopoietic progenitors and hemocyte lineages in the Drosophila lymph gland. Dev. Biol. 346, 310-319. doi: 10.1016/j.ydbio.2010.08.003

Kurant, E. (2011). Keeping the CNS clear: glial phagocytic functions in Drosophila. Glia 59, 1304-1311. doi: 10.1002/glia.21098

Kurant, E., Axelrod, S., Leaman, D., and Gaul, U. (2008). Six-microns-under acts upstream of Draper in the glial phagocytosis of apoptotic neurons. Cell 133, 498-509. doi: 10.1016/j.cell.2008.02.052

Kurucz, É, Márkus, R., Zsámboki, J., Folkl-Medzihradszky, K., Darula, Z., Vilmos, P., et al. (2007). Nimrod, a putative phagocytosis receptor with EGF repeats in Drosophila plasmatocytes. Curr. Biol. 17, 649-654. doi: 10.1016/j.cub.2007. 02.041

Kwon, Y., Song, W., Droujinine, I. A., Hu, Y., Asara, J. M., and Perrimon, N. (2015). Systemic organ wasting induced by localized expression of the secreted insulin/IGF antagonist ImpL2. Dev. Cell 33, 36-46. doi: 10.1016/j.devcel.2015. 02.012

Landgraf, M., and Thor, S. (2006). Development of Drosophila motoneurons: specification and morphology. Semin. Cell Dev. Biol. 17, 3-11. doi: 10.1016/j. semcdb.2005.11.007

Lantz, C., Radmanesh, B., Liu, E., Thorp, E. B., and Lin, J. (2020). Single-cell RNA sequencing uncovers heterogenous transcriptional signatures in macrophages during efferocytosis. Sci. Rep. 10, 14333. doi: 10.1038/s41598-020-70353-y

Lavin, Y., Mortha, A., Rahman, A., and Merad, M. (2015). Regulation of macrophage development and function in peripheral tissues. Nat. Rev. Immunol. 15, 731-744. doi: 10.1038/nri3920

Lavin, Y., Winter, D., Blecher-Gonen, R., David, E., Keren-Shaul, H., Merad, M., et al. (2014). Tissue-resident macrophage enhancer landscapes are shaped by the local microenvironment. Cell 159, 1312-1326. doi: 10.1016/j.cell.2014. 11.018

Lazzaro, B. P. (2008). Natural selection on the Drosophila antimicrobial immune system. Curr. Opin. Microbiol. 11, 284-289. doi: 10.1016/j.mib.2008.05.001
Lebestky, T., Chang, T., Hartenstein, V., and Banerjee, U. (2000). Specification of Drosophila hematopoietic lineage by conserved transcription factors. Science 288, 146-149. doi: 10.1126/science.288.5463.146

Lebestky, T., Jung, S.-H., and Banerjee, U. (2003). A Serrate-expressing signaling center controls Drosophila hematopoiesis. Genes Dev. 17, 348-353. doi: 10.1101/ gad.1052803

LeBleu, V. S., Macdonald, B., and Kalluri, R. (2007). Structure and function of basement membranes. Exp. Biol. Med. (Maywood) 232, 1121-1129. doi: 10. 3181/0703-MR-72

Leitão, A. B., and Sucena, É (2015). Drosophila sessile hemocyte clusters are true hematopoietic tissues that regulate larval blood cell differentiation. eLife 4:e06166. doi: 10.7554/eLife.06166

Lemaitre, B., and Hoffmann, J. (2007). The host defense of Drosophila melanogaster. Annu. Rev. Immunol. 25, 697-743. doi: 10.1146/annurev. immunol.25.022106.141615

Lemaitre, B., Kromer-Metzger, E., Michaut, L., Nicolas, E., Meister, M., Georgel, P., et al. (1995). A recessive mutation, immune deficiency (imd), defines two distinct control pathways in the Drosophila host defense. Proc. Natl. Acad. Sci. U.S.A. 92, 9465-9469. doi: 10.1073/pnas.92.21.9465

Lemaitre, B., and Miguel-Aliaga, I. (2013). The digestive tract of Drosophila melanogaster. Annu. Rev. Genet. 47, 377-404. doi: 10.1146/annurev-genet111212-133343

Lemmon, M. A., and Schlessinger, J. (2010). Cell signaling by receptor tyrosine kinases. Cell 141, 1117-1134. doi: 10.1016/j.cell.2010.06.011

Letourneau, M., Lapraz, F., Sharma, A., Vanzo, N., Waltzer, L., and Crozatier, M. (2016). Drosophila hematopoiesis under normal conditions and in response to immune stress. FEBS Lett. 590, 4034-4051. doi: 10.1002/1873-3468.12327

Li, H., Shuster, S. A., Li, J., and Luo, L. (2018). Linking neuronal lineage and wiring specificity. Neural Dev. 13:5. doi: 10.1186/s13064-018-0102-0

Lin, J.-D., Nishi, H., Poles, J., Niu, X., Mccauley, C., Rahman, K., et al. (2019). Single-cell analysis of fate-mapped macrophages reveals heterogeneity, including stem-like properties, during atherosclerosis progression and regression. JCI Insight 4:e124574. doi: 10.1172/jci.insight.124574

Lundell, M. J. (2003). The regulation of apoptosis by Numb/Notch signaling in the serotonin lineage of Drosophila. Development 130, 4109-4121. doi: 10.1242/dev. 00593

MacDonald, J. M., Beach, M. G., Porpiglia, E., Sheehan, A. E., Watts, R. J., and Freeman, M. R. (2006). The Drosophila cell corpse engulfment receptor Draper mediates glial clearance of severed axons. Neuron 50, 869-881. doi: 10.1016/j. neuron.2006.04.028

Mackenzie, D. K., Bussière, L. F., and Tinsley, M. C. (2011). Senescence of the cellular immune response in Drosophila melanogaster. Exp. Gerontol. 46, 853-859. doi: 10.1016/j.exger.2011.07.004

MacParland, S. A., Liu, J. C., Ma, X.-Z., Innes, B. T., Bartczak, A. M., Gage, B. K., et al. (2018). Single cell RNA sequencing of human liver reveals distinct intrahepatic macrophage populations. Nat. Commun. 9:4383. doi: 10.1038/ s41467-018-06318-7

Maddrell, S. H. P. (1972). The mechanisms of insect excretory systems. Adv. Insect Physiol. 8, 199-331. doi: 10.1016/S0065-2806(08)60198-8

Makhijani, K., Alexander, B., Rao, D., Petraki, S., Herboso, L., Kukar, K., et al. (2017). Regulation of Drosophila hematopoietic sites by Activin- $\beta$ from active sensory neurons. Nat. Commun. 8, 15990. doi: 10.1038/ncomms15990

Makhijani, K., Alexander, B., Tanaka, T., Rulifson, E., and Brückner, K. (2011). The peripheral nervous system supports blood cell homing and survival in the Drosophila larva. Development 138, 5379-5391. doi: 10.1242/dev.067322

Makhijani, K., and Brückner, K. (2012). Of blood cells and the nervous system: hematopoiesis in the Drosophila larva. Fly (Austin) 6, 254-260. doi: 10.4161/fly. 22267

Manaka, J., Kuraishi, T., Shiratsuchi, A., Nakai, Y., Higashida, H., Henson, P., et al. (2004). Draper-mediated and Phosphatidylserine-independent phagocytosis of apoptotic cells by Drosophila hemocytes/macrophages. J. Biol. Chem. 279, 48466-48476. doi: 10.1074/jbc.M408597200

Mandal, L., Martinez-Agosto, J. A., Evans, C. J., Hartenstein, V., and Banerjee, U. (2007). A Hedgehog- and Antennapedia-dependent niche maintains Drosophila haematopoietic precursors. Nature 446, 320-324. doi: 10.1038/nature05585

Manning, G., and Krasnow, M. A. (1993). "Development of the Drosophila tracheal system," in The Development of Drosophila melanogaster, eds M. Bate and A. M. Arias (Cold Spring Harbor, NY: Cold Spring Harbor Laboratory Press). 
Márkus, R., Kurucz, E., Rus, F., and Andó, I. (2005). Sterile wounding is a minimal and sufficient trigger for a cellular immune response in Drosophila melanogaster. Immunol. Lett. 101, 108-111. doi: 10.1016/j.imlet.2005.03.021

Markus, R., Laurinyecz, B., Kurucz, E., Honti, V., Bajusz, I., Sipos, B., et al. (2009). Sessile hemocytes as a hematopoietic compartment in Drosophila melanogaster. Proc. Natl. Acad. Sci. U.S.A. 106, 4805-4809. doi: 10.1073/pnas.0801766106

Martinek, N., Shahab, J., Saathoff, M., and Ringuette, M. (2011). Haemocytederived SPARC is required for collagen-IV-dependent stability of basal laminae in Drosophila embryos. J. Cell Sci. 124:670. doi: 10.1242/jcs.086819

Martinez, F. O. (2008). Macrophage activation and polarization. Front. Biosci. 13:453. doi: $10.2741 / 2692$

Martinez, F. O., Gordon, S., Locati, M., and Mantovani, A. (2006). Transcriptional profiling of the human monocyte-to-macrophage differentiation and polarization: new molecules and patterns of gene expression. J. Immunol. 177, 7303-7311. doi: 10.4049/jimmunol.177.10.7303

Matsubayashi, Y., Louani, A., Dragu, A., Sánchez-Sánchez, B. J., Serna-Morales, E., Yolland, L., et al. (2017). A moving source of matrix components is essential for de novo basement membrane formation. Curr. Biol. 27, 3526-3534.e4. doi: 10.1016/j.cub.2017.10.001

McClure, K. D., Sustar, A., and Schubiger, G. (2008). Three genes control the timing, the site and the size of blastema formation in Drosophila. Dev. Biol. 319, 68-77. doi: 10.1016/j.ydbio.2008.04.004

Melcarne, C., Ramond, E., Dudzic, J., Bretscher, A. J., Kurucz, É, Andó, I., et al. (2019). Two Nimrod receptors, NimC1 and Eater, synergistically contribute to bacterial phagocytosis in Drosophila melanogaster. FEBS J. 286, 2670-2691. doi: $10.1111 /$ febs. 14857

Merad, M., Manz, M. G., Karsunky, H., Wagers, A., Peters, W., Charo, I., et al. (2002). Langerhans cells renew in the skin throughout life under steady-state conditions. Nat. Immunol. 3, 1135-1141. doi: 10.1038/ni852

Micchelli, C. A., and Perrimon, N. (2006). Evidence that stem cells reside in the adult Drosophila midgut epithelium. Nature 439, 475-479. doi: 10.1038/ nature 04371

Miguel-Aliaga, I. (2004). Segment-specific prevention of pioneer neuron apoptosis by cell-autonomous, postmitotic Hox gene activity. Development 131, 60936105. doi: 10.1242/dev.01521

Miller, J. M., Oligino, T., Pazdera, M., López, A. J., and Hoshizaki, D. K. (2002). Identification of fat-cell enhancer regions in Drosophila melanogaster. Insect Mol. Biol. 11, 67-77. doi: 10.1046/j.0962-1075.2001.00310.x

Milton, C. C., Grusche, F. A., Degoutin, J. L., Yu, E., Dai, Q., Lai, E. C., et al. (2014). The Hippo pathway regulates hematopoiesis in Drosophila melanogaster. Curr. Biol. 24, 2673-2680. doi: 10.1016/j.cub.2014.10.031

Minakhina, S., Druzhinina, M., and Steward, R. (2007). Zfrp8, the Drosophila ortholog of PDCD2, functions in lymph gland development and controls cell proliferation. Development 134, 2387-2396. doi: 10.1242/dev.003616

Minakhina, S., Tan, W., and Steward, R. (2011). JAK/STAT and the GATA factor Pannier control hemocyte maturation and differentiation in Drosophila. Dev. Biol. 352, 308-316. doi: 10.1016/j.ydbio.2011.01.035

Morrison, S. J., and Scadden, D. T. (2014). The bone marrow niche for haematopoietic stem cells. Nature 505, 327-334. doi: 10.1038/nature12984

Mosser, D. M., and Edwards, J. P. (2008). Exploring the full spectrum of macrophage activation. Nat. Rev. Immunol. 8, 958-969. doi: 10.1038/nri2448

Mould, K. J., Jackson, N. D., Henson, P. M., Seibold, M., and Janssen, W. J. (2019). Single cell RNA sequencing identifies unique inflammatory airspace macrophage subsets. JCI Insight 4:e126556. doi: 10.1172/jci.insight.126556

Munier, A., Doucet, D., Perrodou, E., Zachary, D., Meister, M., Hoffmann, J. A., et al. (2002). PVF2, a PDGF/VEGF-like growth factor, induces hemocyte proliferation in Drosophila larvae. EMBO Rep. 3, 1195-1200. doi: 10.1093/ embo-reports/kvf242

Munro, D. A. D., and Hughes, J. (2017). The origins and functions of tissueresident macrophages in kidney development. Front. Physiol. 8:837. doi: 10. 3389/fphys.2017.00837

Murakami, R., Takashima, S., and Hamaguchi, T. (1999). Developmental genetics of the Drosophila gut: specification of primordia, subdivision and overtdifferentiation. Cell Mol. Biol. 45, 661-676.

Myrick, K. V., and Dearolf, C. R. (2000). Hyperactivation of the Drosophila Hop Jak kinase causes the preferential overexpression of eIF1A transcripts in larval blood cells. Gene 244, 119-125. doi: 10.1016/S0378-1119(99)00568-5
Nehme, N. T., Liégeois, S., Kele, B., Giammarinaro, P., Pradel, E., Hoffmann, J. A., et al. (2007). A model of bacterial intestinal infections in Drosophila melanogaster. PLoS Pathog. 3:e173. doi: 10.1371/journal.ppat.0030173

Nelliot, A., Bond, N., and Hoshizaki, D. K. (2006). Fat-body remodeling in Drosophila melanogaster. Genesis 44, 396-400. doi: 10.1002/dvg.20229

Nelson, R. E., Fessler, L. I., Takagi, Y., Blumberg, B., Keene, D. R., Olson, P. F., et al. (1994). Peroxidasin: a novel enzyme-matrix protein of Drosophila development. EMBO J. 13, 3438-3447.

Neves, J., Zhu, J., Sousa-Victor, P., Konjikusic, M., Riley, R., Chew, S., et al. (2016). Immune modulation by MANF promotes tissue repair and regenerative success in the retina. Science 353:aaf3646. doi: 10.1126/science.aaf3646

Nicolás-Ávila, J. A., Lechuga-Vieco, A. V., Esteban-Martínez, L., Sánchez-Díaz, M., Díaz-García, E., Santiago, D. J., et al. (2020). A network of macrophages supports mitochondrial homeostasis in the heart. Cell 183, 94-109.e23. doi: 10.1016/j.cell.2020.08.031

Nonaka, S., Ando, Y., Kanetani, T., Hoshi, C., Nakai, Y., Nainu, F., et al. (2017) Signaling pathway for phagocyte priming upon encounter with apoptotic cells. J. Biol. Chem. 292, 8059-8072. doi: 10.1074/jbc.M116.769745

Ocorr, K., Perrin, L., Lim, H.-Y., Qian, L., Wu, X., and Bodmer, R. (2007). Genetic control of heart function and aging in Drosophila. Trends Cardiovasc. Med. 17, 177-182. doi: 10.1016/j.tcm.2007.04.001

Ohlstein, B., and Spradling, A. (2006). The adult Drosophila posterior midgut is maintained by pluripotent stem cells. Nature 439, 470-474. doi: 10.1038/ nature 04333

Okabe, Y., and Medzhitov, R. (2016). Tissue biology perspective on macrophages. Nat. Immunol. 17, 9-17. doi: 10.1038/ni.3320

Olofsson, B., and Page, D. T. (2005). Condensation of the central nervous system in embryonic Drosophila is inhibited by blocking hemocyte migration or neural activity. Dev. Biol. 279, 233-243. doi: 10.1016/j.ydbio.2004.12.020

Ouyang, D., Xiao, X., Mase, A., Li, G., Corcoran, S., Wang, F., et al. (2020). Dscam1 promotes blood cell survival in Drosophila melanogaster through a dual role in blood cells and neurons. bioRxiv [Preprint] doi: 10.1101/2020.09.26.314997

Owusu-Ansah, E., and Banerjee, U. (2009). Reactive oxygen species prime Drosophila haematopoietic progenitors for differentiation. Nature 461, 537541. doi: 10.1038/nature08313

Pandey, R., Blanco, J., and Udolph, G. (2011). The glucuronyltransferase GlcAT$\mathrm{P}$ is required for stretch growth of peripheral nerves in Drosophila. PLoS One 6:e28106. doi: 10.1371/journal.pone.0028106

Parkin, C. A., and Burnet, B. (1986). Growth arrest of Drosophila melanogaster on erg-2 and erg-6 sterol mutant strains of Saccharomyces cerevisiae. J. Insect Physiol. 32, 463-471. doi: 10.1016/0022-1910(86)90007-7

Parsons, B., and Foley, E. (2013). The Drosophila platelet-derived growth factor and vascular endothelial growth factor-receptor related (Pvr) protein ligands Pvf2 and Pvf3 control hemocyte viability and invasive migration. J. Biol. Chem. 288, 20173-20183. doi: 10.1074/jbc.M113.483818

Parupalli, P., Tomar, A., Madhwal, S., and Mukherjee, T. (2020). Immune control of animal growth in homeostasis and nutritional stress in Drosophila. Front. Immunol. 11:1528. doi: 10.3389/fimmu.2020.01528

Pastor-Pareja, J. C., Wu, M., and Xu, T. (2008). An innate immune response of blood cells to tumors and tissue damage in Drosophila. Dis. Models Mech. 1, 144-154. doi: 10.1242/dmm.000950

Paul, F., Arkin, Y., Giladi, A., Jaitin, D. A., Kenigsberg, E., Keren-Shaul, H., et al. (2015). Transcriptional heterogeneity and lineage commitment in myeloid progenitors. Cell 163, 1663-1677. doi: 10.1016/j.cell.2015.11.013

Pennetier, D., Oyallon, J., Morin-Poulard, I., Dejean, S., Vincent, A., and Crozatier, M. (2012). Size control of the Drosophila hematopoietic niche by bone morphogenetic protein signaling reveals parallels with mammals. Proc. Natl. Acad. Sci. U.S.A. 109, 3389-3394. doi: 10.1073/pnas.1109407109

Perdiguero, E. G., and Geissmann, F. (2016). The development and maintenance of resident macrophages. Nat. Immunol. 17, 2-8. doi: 10.1038/ni.3341

Peterson, C., Carney, G. E., Taylor, B. J., and White, K. (2002). reaper is required for neuroblast apoptosis during Drosophila development. Development 129, 1467-1476.

Petraki, S., Alexander, B., and Brückner, K. (2015). Assaying blood cell populations of the Drosophila melanogaster larva. J. Vis. Exp. 105, 52733. doi: 10.3791/52733

Pull, S. L., Doherty, J. M., Mills, J. C., Gordon, J. I., and Stappenbeck, T. S. (2005). Activated macrophages are an adaptive element of the colonic epithelial 
progenitor niche necessary for regenerative responses to injury. Proc. Natl. Acad. Sci. U.S.A. 102, 99-104. doi: 10.1073/pnas.0405979102

Qiu, P., Pan, P. C., and Govind, S. (1998). A role for the Drosophila Toll/Cactus pathway in larval hematopoiesis. Development 125, 1909-1920.

Ramond, E., Dudzic, J. P., and Lemaitre, B. (2020a). Comparative RNA-Seq analyses of Drosophila plasmatocytes reveal gene specific signatures in response to clean injury and septic injury. PLoS One 15:e0235294. doi: 10.1371/journal. pone.0235294

Ramond, E., Petrignani, B., Dudzic, J. P., Boquete, J., Poidevin, M., Kondo, S., et al. (2020b). The adipokine NimrodB5 regulates peripheral hematopoiesis in Drosophila. FEBS J. 287, 3399-3426. doi: 10.1111/febs.15237

Raoof, R., van der Vlist, M., Willemen, H. L. D. M., Prado, J., Versteeg, S., Vos, M., et al. (2020). Macrophages transfer mitochondria to sensory neurons to resolve inflammatory pain. bioRxiv [Preprint] doi: 10.1101/2020.02.12.940445

Ratheesh, A., Belyaeva, V., and Siekhaus, D. E. (2015). Drosophila immune cell migration and adhesion during embryonic development and larval immune responses. Curr. Opin. Cell Biol. 36, 71-79. doi: 10.1016/j.ceb.2015.07.003

Regan, J. C., Brandão, A. S., Leitão, A. B., Mantas Dias, A. R., Sucena, E., Jacinto, A., et al. (2013). Steroid hormone signaling is essential to regulate innate immune cells and fight bacterial infection in Drosophila. PLoS Pathog. 9:e1003720. doi: 10.1371/journal.ppat.1003720

Roddie, H. G., Armitage, E. L., Coates, J. A., Johnston, S. A., and Evans, I. R. (2019). Simu-dependent clearance of dying cells regulates macrophage function and inflammation resolution. PLoS Biol. 17:e2006741. doi: 10.1371/journal.pbio. 2006741

Rogulja-Ortmann, A., Luer, K., Seibert, J., Rickert, C., and Technau, G. M. (2007). Programmed cell death in the embryonic central nervous system of Drosophila melanogaster. Development 134, 105-116. doi: 10.1242/dev.02707

Ryoo, H. D., Gorenc, T., and Steller, H. (2004). Apoptotic cells can induce compensatory cell proliferation through the JNK and the Wingless signaling pathways. Dev. Cell 7, 491-501. doi: 10.1016/j.devcel.2004.08.019

Sampson, C. J., Amin, U., and Couso, J.-P. (2013). Activation of Drosophila hemocyte motility by the ecdysone hormone. Biol. Open 2, 1412-1420. doi: 10.1242/bio.20136619

Sanchez Bosch, P., Makhijani, K., Herboso, L., Gold, K. S., Baginsky, R., Woodcock, K. J., et al. (2019). Adult Drosophila lack hematopoiesis but rely on a blood cell reservoir at the respiratory epithelia to relay infection signals to surrounding tissues. Dev. Cell 51, 787-803.e5. doi: 10.1016/j.devcel.2019.10.017

Sánchez-Sánchez, B. J., Urbano, J. M., Comber, K., Dragu, A., Wood, W., Stramer, B., et al. (2017). Drosophila embryonic hemocytes produce laminins to strengthen migratory response. Cell Rep. 21, 1461-1470. doi: 10.1016/j.celrep. 2017.10.047

Sánchez-Soriano, N., Tear, G., Whitington, P., and Prokop, A. (2007). Drosophila as a genetic and cellular model for studies on axonal growth. Neural Dev. 2, 9. doi: 10.1186/1749-8104-2-9

Santabárbara-Ruiz, P., López-Santillán, M., Martínez-Rodríguez, I., Binagui-Casas, A., Pérez, L., Milán, M., et al. (2015). ROS-induced JNK and p38 signaling is required for unpaired cytokine activation during Drosophila regeneration. PLoS Genet. 11:e1005595. doi: 10.1371/journal.pgen.1005595

Schirmeier, S., Matzat, T., and Klämbt, C. (2016). Axon ensheathment and metabolic supply by glial cells in Drosophila. Brain Res. 1641, 122-129. doi: 10.1016/j.brainres.2015.09.003

Schmid, M. R., Anderl, I., Vesala, L., Vanha-aho, L.-M., Deng, X.-J., Rämet, M., et al. (2014). Control of Drosophila blood cell activation via Toll signaling in the fat body. PLoS One 9:e102568. doi: 10.1371/journal.pone.0102568

Schulz, C., Gomez Perdiguero, E., Chorro, L., Szabo-Rogers, H., Cagnard, N., Kierdorf, K., et al. (2012). A lineage of myeloid cells independent of Myb and hematopoietic stem cells. Science 336, 86-90. doi: 10.1126/science.1219179

Sears, H. C. (2003). Macrophage-mediated corpse engulfment is required for normal Drosophila CNS morphogenesis. Development 130, 3557-3565. doi: 10.1242/dev.00586

Sessions, A. O., Kaushik, G., Parker, S., Raedschelders, K., Bodmer, R., Van Eyk, J. E., et al. (2017). Extracellular matrix downregulation in the Drosophila heart preserves contractile function and improves lifespan. Matrix Biol. 62, 15-27. doi: 10.1016/j.matbio.2016.10.008

Shahab, J., Baratta, C., Scuric, B., Godt, D., Venken, K. J. T., and Ringuette, M. J. (2015). Loss of SPARC dysregulates basal lamina assembly to disrupt larval fat body homeostasis in Drosophila melanogaster. Dev. Dyn. 244, 540-552. doi: $10.1002 /$ dvdy.24243

Shapouri-Moghaddam, A., Mohammadian, S., Vazini, H., Taghadosi, M., Esmaeili, S.-A., Mardani, F., et al. (2018). Macrophage plasticity, polarization, and function in health and disease. J. Cell Physiol. 233, 6425-6440. doi: 10.1002/ jcp. 26429

Shia, A. K. H., Glittenberg, M., Thompson, G., Weber, A. N., Reichhart, J.M., and Ligoxygakis, P. (2009). Toll-dependent antimicrobial responses in Drosophila larval fat body require Spätzle secreted by haemocytes. J. Cell Sci. 122, 4505-4515. doi: 10.1242/jcs.049155

Shim, J., Mukherjee, T., and Banerjee, U. (2012). Direct sensing of systemic and nutritional signals by haematopoietic progenitors in Drosophila. Nat. Cell Biol. 14, 394-400. doi: 10.1038/ncb2453

Shim, J., Mukherjee, T., Mondal, B. C., Liu, T., Young, G. C., Wijewarnasuriya, D. P., et al. (2013). Olfactory control of blood progenitor maintenance. Cell 155, 1141-1153. doi: 10.1016/j.cell.2013.10.032

Shin, M., Cha, N., Koranteng, F., Cho, B., and Shim, J. (2020). Subpopulation of macrophage-like plasmatocytes attenuates systemic growth via JAK/STAT in the Drosophila fat body. Front. Immunol. 11:63. doi: 10.3389/fimmu.2020. 00063

Shklyar, B., Sellman, Y., Shklover, J., Mishnaevski, K., Levy-Adam, F., and Kurant, E. (2014). Developmental regulation of glial cell phagocytic function during Drosophila embryogenesis. Dev. Biol. 393, 255-269. doi: 10.1016/j.ydbio.2014. 07.005

Shlyakhover, E., Shklyar, B., Hakim-Mishnaevski, K., Levy-Adam, F., and Kurant, E. (2018). Drosophila GATA factor serpent establishes phagocytic ability of embryonic macrophages. Front. Immunol. 9:266. doi: 10.3389/fimmu.2018. 00266

Siekhaus, D., Haesemeyer, M., Moffitt, O., and Lehmann, R. (2010). RhoL controls invasion and Rap1 localization during immune cell transmigration in Drosophila. Nat. Cell Biol. 12, 605-610. doi: 10.1038/ncb2063

Sieweke, M. H., and Allen, J. E. (2013). Beyond stem cells: self-renewal of differentiated macrophages. Science 342:1242974. doi: 10.1126/science.1242974

Sinenko, S. A., Mandal, L., Martinez-Agosto, J. A., and Banerjee, U. (2009). Dual role of wingless signaling in stem-like hematopoietic precursor maintenance in Drosophila. Dev. Cell 16, 756-763. doi: 10.1016/j.devcel.2009.03.003

Singhania, A., and Grueber, W. B. (2014). Development of the embryonic and larval peripheral nervous system of Drosophila. Wiley Interdiscip. Rev. Dev. Biol. 3, 193-210. doi: 10.1002/wdev.135

Song, W., Onishi, M., Jan, L. Y., and Jan, Y. N. (2007). Peripheral multidendritic sensory neurons are necessary for rhythmic locomotion behavior in Drosophila larvae. Proc. Natl. Acad. Sci. U.S.A. 104, 5199-5204. doi: 10.1073/pnas. 0700895104

Sonnenfeld, M. J., and Jacobs, J. R. (1995). Macrophages and glia participate in the removal of apoptotic neurons from theDrosophila embryonic nervous system. J. Comp. Neurol. 359, 644-652. doi: 10.1002/cne.903590410

Sopko, R., Lin, Y. B., Makhijani, K., Alexander, B., Perrimon, N., and Brückner, K. (2015). A systems-level interrogation identifies regulators of Drosophila blood cell number and survival. PLoS Genet. 11:e1005056. doi: 10.1371/journal.pgen. 1005056

Sorrentino, R. P., Carton, Y., and Govind, S. (2002). Cellular immune response to parasite infection in the Drosophila lymph gland is developmentally regulated. Dev. Biol. 243, 65-80. doi: 10.1006/dbio.2001.0542

Stanley, E. R., and Chitu, V. (2014). CSF-1 receptor signaling in myeloid cells. Cold Spring Harb. Perspect. Biol. 6:a021857. doi: 10.1101/cshperspect.a021857

Stofanko, M., Kwon, S. Y., and Badenhorst, P. (2008). A misexpression screen to identify regulators of drosophila larval hemocyte development. Genetics 180, 253-267. doi: 10.1534/genetics.108.089094

Stramer, B., Wood, W., Galko, M. J., Redd, M. J., Jacinto, A., Parkhurst, S. M., et al. (2005). Live imaging of wound inflammation in Drosophila embryos reveals key roles for small GTPases during in vivo cell migration. J. Cell Biol. 168, 567-573. doi: $10.1083 /$ jcb. 200405120

Sugie, A., Marchetti, G., and Tavosanis, G. (2018). Structural aspects of plasticity in the nervous system of Drosophila. Neural Dev. 13:14. doi: 10.1186/s13064-0180111-z

Takeishi, A., Kuranaga, E., Tonoki, A., Misaki, K., Yonemura, S., Kanuka, H., et al. (2013). Homeostatic epithelial renewal in the gut is required for dampening a 
fatal systemic wound response in Drosophila. Cell Rep. 3, 919-930. doi: 10.1016/ j.celrep.2013.02.022

Tarique, A. A., Logan, J., Thomas, E., Holt, P. G., Sly, P. D., and Fantino, E. (2015). Phenotypic, functional, and plasticity features of classical and alternatively activated human macrophages. Am. J. Respir. Cell Mol. Biol. 53, 676-688. doi: 10.1165/rcmb.2015-0012OC

Tattikota, S. G., Cho, B., Liu, Y., Hu, Y., Barrera, V., Steinbaugh, M. J., et al. (2020). A single-cell survey of Drosophila blood. eLife 9:e54818. doi: 10.7554/ eLife. 54818

Tepass, U., Fessler, L. I., Aziz, A., and Hartenstein, V. (1994). Embryonic origin of hemocytes and their relationship to cell death in Drosophila. Development 120, 1829-1837.

Tracey, W. D., Wilson, R. I., Laurent, G., and Benzer, S. (2003). painless, a Drosophila gene essential for nociception. Cell 113, 261-273. doi: 10.1016/ S0092-8674(03)00272-1

Trébuchet, G., Cattenoz, P. B., Zsámboki, J., Mazaud, D., Siekhaus, D. E., Fanto, M., et al. (2019). The repo homeodomain transcription factor suppresses hematopoiesis in Drosophila and preserves the glial fate. J. Neurosci. 39, 238255. doi: 10.1523/JNEUROSCI.1059-18.2018

Tzou, P., Ohresser, S., Ferrandon, D., Capovilla, M., Reichhart, J. M., Lemaitre, B., et al. (2000). Tissue-specific inducible expression of antimicrobial peptide genes in Drosophila surface epithelia. Immunity 13, 737-748. doi: 10.1016/s10747613(00)00072-8

Van De Bor, V., Zimniak, G., Papone, L., Cerezo, D., Malbouyres, M., Juan, T., et al. (2015). Companion blood cells control ovarian stem cell niche microenvironment and homeostasis. Cell Rep. 13, 546-560. doi: 10.1016/j. celrep.2015.09.008

van Furth, R., Cohn, Z. A., Hirsch, J. G., Humphrey, J. H., Spector, W. G., and Langevoort, H. L. (1972). The mononuclear phagocyte system: a new classification of macrophages, monocytes, and their precursor cells. Bull. World Health Organ. 46, 845-852.

Van Hove, H., Martens, L., Scheyltjens, I., De Vlaminck, K., Pombo Antunes, A. R., De Prijck, S., et al. (2019). A single-cell atlas of mouse brain macrophages reveals unique transcriptional identities shaped by ontogeny and tissue environment. Nat. Neurosci. 22, 1021-1035. doi: 10.1038/s41593-019-0393-4

Vanha-aho, L.-M., Anderl, I., Vesala, L., Hultmark, D., Valanne, S., and Rämet, M. (2015). Edin expression in the fat body is required in the defense against parasitic wasps in Drosophila melanogaster. PLoS Pathog. 11:e1004895. doi: 10.1371/journal.ppat.1004895

Varga, V. B., Szikszai, F., Szinyákovics, J., Manzéger, A., Puska, G., Kovács, T., et al. (2020). Role of hemocytes in the regeneration of germline stem cells in Drosophila. bioRxiv [Preprint] doi: 10.1101/2020.08.31.275255

Wang, L., Kounatidis, I., and Ligoxygakis, P. (2014). Drosophila as a model to study the role of blood cells in inflammation, innate immunity and cancer. Front. Cell. Infect. Microbiol. 3:113. doi: 10.3389/fcimb.2013.00113

Wang, X., Harris, R. E., Bayston, L. J., and Ashe, H. L. (2008). Type IV collagens regulate BMP signalling in Drosophila. Nature 455, 72-77.

Watts, R. J., Schuldiner, O., Perrino, J., Larsen, C., and Luo, L. (2004). Glia engulf degenerating axons during developmental axon pruning. Curr. Biol. 14, 678-684. doi: 10.1016/j.cub.2004.03.035

Weavers, H., Evans, I. R., Martin, P., and Wood, W. (2016). Corpse engulfment generates a molecular memory that primes the macrophage inflammatory response. Cell 165, 1658-1671. doi: 10.1016/j.cell.2016.04.049

Weinstock, A., Brown, E. J., Garabedian, M. L., Pena, S., Sharma, M., Lafaille, J., et al. (2019). Single-cell RNA sequencing of visceral adipose tissue leukocytes reveals that caloric restriction following obesity promotes the accumulation of a distinct macrophage population with features of phagocytic cells. Immunometabolism 1:e190008. doi: 10.20900/immunometab20190008

Welman, A., Serrels, A., Brunton, V. G., Ditzel, M., and Frame, M. C. (2010). Twocolor photoactivatable probe for selective tracking of proteins and cells. J. Biol. Chem. 285, 11607-11616. doi: 10.1074/jbc.M110.102392

White, K., Grether, M. E., Abrams, J. M., Young, L., Farrell, K., and Steller, H. (1994). Genetic control of programmed cell death in Drosophila. Science 264, 677-683. doi: 10.1126/science.8171319

Whitten, J. M. (1957). The post-embryonic development of the tracheal system in Drosophila melanogaster. J. Cell Sci. 98, 123.

Williams, D. W. (2005). Cellular mechanisms of dendrite pruning in Drosophila: insights from in vivo time-lapse of remodeling dendritic arborizing sensory neurons. Development 132, 3631-3642. doi: 10.1242/dev.01928
Williams, M. J. (2006). Rac1 signalling in the Drosophila larval cellular immune response. J. Cell Sci. 119, 2015-2024. doi: 10.1242/jcs.02920

Wood, W., Faria, C., and Jacinto, A. (2006). Distinct mechanisms regulate hemocyte chemotaxis during development and wound healing in Drosophila melanogaster. J. Cell Biol. 173, 405-416. doi: 10.1083/jcb.200508161

Wood, W., and Jacinto, A. (2007). Drosophila melanogaster embryonic haemocytes: masters of multitasking. Nat. Rev. Mol. Cell Biol. 8, 542-551. doi: 10.1038/ nrm2202

Woodcock, K. J., Kierdorf, K., Pouchelon, C. A., Vivancos, V., Dionne, M. S., and Geissmann, F. (2015). Macrophage-derived upd3 cytokine causes impaired glucose homeostasis and reduced lifespan in Drosophila fed a lipid-rich diet. Immunity 42, 133-144. doi: 10.1016/j.immuni.2014.12.023

Worley, M. I., Setiawan, L., and Hariharan, I. K. (2012). Regeneration and transdetermination in Drosophila imaginal discs. Annu. Rev. Genet. 46, 289310. doi: 10.1146/annurev-genet-110711-155637

Wu, R., Van der Hoek, K. H., Ryan, N. K., Norman, R. J., and Robker, R. L. (2004). Macrophage contributions to ovarian function. Hum. Reprod. Update 10, 119-133. doi: 10.1093/humupd/dmh011

Xiang, Y., Yuan, Q., Vogt, N., Looger, L. L., Jan, L. Y., and Jan, Y. N. (2010). Light-avoidance-mediating photoreceptors tile the Drosophila larval body wall. Nature 468, 921-926. doi: 10.1038/nature09576

Xue, J., Schmidt, S. V., Sander, J., Draffehn, A., Krebs, W., Quester, I., et al. (2014). Transcriptome-based network analysis reveals a spectrum model of human macrophage activation. Immunity 40, 274-288. doi: 10.1016/j.immuni.2014. 01.006

Yang, H., and Hultmark, D. (2017). Drosophila muscles regulate the immune response against wasp infection via carbohydrate metabolism. Sci. Rep. 7:15713. doi: 10.1038/s41598-017-15940-2

Yang, H., Kronhamn, J., Ekström, J.-O., Korkut, G. G., and Hultmark, D. (2015). JAK/STAT signaling in Drosophila muscles controls the cellular immune response against parasitoid infection. EMBO Rep. 16, 1664-1672. doi: 10.15252/ embr.201540277

Yurchenco, P. D. (2011). Basement membranes: cell scaffoldings and signaling platforms. Cold Spring Harb. Perspect. Biol. 3:a004911. doi: 10.1101/cshperspect. a004911

Zaidman-Rémy, A., Regan, J. C., Brandão, A. S., and Jacinto, A. (2012). The Drosophila larva as a tool to study gut-associated macrophages: PI3K regulates a discrete hemocyte population at the proventriculus. Dev. Comp. Immunol. 36, 638-647. doi: 10.1016/j.dci.2011.10.013

Zhang, Y., and Xi, Y. (2015). Fat body development and its function in energy storage and nutrient sensing in Drosophila melanogaster. J. Tissue Sci. Eng. 6:1. doi: 10.4172/2157-7552.1000141

Zheng, Q., Ma, A., Yuan, L., Gao, N., Feng, Q., Franc, N. C., et al. (2017). Apoptotic cell clearance in Drosophila melanogaster. Front. Immunol. 8:1881. doi: 10.3389/fimmu.2017.01881

Zhou, J., Florescu, S., Boettcher, A.-L., Luo, L., Dutta, D., Kerr, G., et al. (2015). $\mathrm{Dpp} / \mathrm{Gbb}$ signaling is required for normal intestinal regeneration during infection. Dev. Biol. 399, 189-203. doi: 10.1016/j.ydbio.2014.12.017

Zhou, L., Hashimi, H., Schwartz, L. M., and Nambu, J. R. (1995). Programmed cell death in the Drosophila central nervous system midline. Curr. Biol. 5, 784-790. doi: 10.1016/S0960-9822(95)00155-2

Zhu, L., Zhao, Q., Yang, T., Ding, W., and Zhao, Y. (2015). Cellular metabolism and macrophage functional polarization. Int. Rev. Immunol. 34, 82-100. doi: 10.3109/08830185.2014.969421

Zimmerman, K. A., Bentley, M. R., Lever, J. M., Li, Z., Crossman, D. K., Song, C. J., et al. (2019). Single-cell RNA sequencing identifies candidate renal resident macrophage gene expression signatures across species. J. Am. Soc. Nephrol. 30, 767-781. doi: 10.1681/ASN.2018090931

Conflict of Interest: The authors declare that the research was conducted in the absence of any commercial or financial relationships that could be construed as a potential conflict of interest.

Copyright $\odot 2021$ Mase, Augsburger and Brückner. This is an open-access article distributed under the terms of the Creative Commons Attribution License (CC BY). The use, distribution or reproduction in other forums is permitted, provided the original author(s) and the copyright owner(s) are credited and that the original publication in this journal is cited, in accordance with accepted academic practice. No use, distribution or reproduction is permitted which does not comply with these terms. 